\title{
Geologia do depósito de Au Cavalo Branco (Botuverá - SC)
}

\author{
João Carlos Biondi ${ }^{1}$, Nilton Djalmo Franke ${ }^{2}$, Paulo Roberto de Carvalho ${ }^{3}$ \\ \& Sandro Notto Villanova ${ }^{3}$
}

\begin{abstract}
Resumo Cavalo Branco é um depósito filoneano de quartzo com ouro, com recursos estimados em 1 a 2 toneladas de metal contido e teores entre 2 e $40 \mathrm{~g} \mathrm{Au} /$ ton, situado na região de Botuverá (SC). O depósito está geneticamente relacionado a um pequeno plutão diorítico seccionado por uma fratura conjugada a uma zona de cisalhamento. Está encaixado por metapelitos do Grupo Brusque, termometamorfisados por plutões graníticos situados em torno do depósito. O fluído mineralizador que gerou o depósito formou zonas de alteração hidrotermal potássica, fílica e propilítica. O ouro, junto a muito pouca pirita, calcopirita e galena, cristalizou durante a formação da zona fílica. Uma reativação da zona de cisalhamento deformou parte do filão mineralizado, propiciou a intrusão de vênulas e diques de granito rosado e trouxe fluídos hidrotermais que remobilizaram os sulfetos e o ouro da zona cisalhada do depósito e carbonatizaram e cloritizaram suas encaixantes. $\mathrm{O}$ ouro recristalizado tem teores de prata $(23,20 \%)$ e de cobre $(0,51 \%)$ pouco maiores que o ouro primário $(19,95 \%$ e $0,01 \%$, respectivamente), mas os sulfetos não tiveram suas composições alteradas. As características da mineralização primária são as de um filão aurífero plutogênico periplutônico. Embora a reativação tenha mudado a composição do ouro e os estilos da alteração das encaixantes, essas modificações não justificam a classificação do depósito como "orogênico". O diorito que gerou o depósito e o granito das vênulas e veios que se alojaram no local do depósito durante a reativação do cisalhamento, são de fácies até então desconhecidas na região.
\end{abstract}

Palavras Chave: Geologia de depósito mineral, Cavalo Branco (SC), ouro, hidrotermalismo, mineralogia.

\begin{abstract}
Geology of Cavalo Branco gold deposit (Botuverá, SC, Brazil). Cavalo Branco is a quartzvein gold deposit located in the Botuverá region (SC, Brazil). The deposit is genetically related to the emplacement of a small diorite pluton in a conjugated fracture of a shear zone affecting metapelitic hornfels from the Brusque Group, formed by granitic plutons emplaced around the deposit. The mineralizing fluid that formed the gold quartz vein has generated potassic, phyllic and propilithic hydrothermal zones around the vein. Gold, with small amounts of pyrite, chalcopyrite and galena, has crystallized during the development of the phyllic zone. A shear zone reactivation has deformed part of the gold bearing quartz vein and provided the rising of pink granite veins. New hydrothermal fluids related with the reactivation displaced gold and sulfides from the sheared portion of the deposit and promote carbonatization and chloritization of the host rocks. Recrystallized gold shows silver $(23,20 \%)$ and copper $(0,51 \%)$ grades a little higher than primary crystallized gold $(19,95 \% \mathrm{e}$ $0,01 \%$, respectivelly). Recrystallization has not changed the sulfide compositions. Primary mineralization has the same characteristics of periplutonic granitogenic gold veins. Although the shear reactivation has changed gold composition and the alteration style of the host rocks, these changes are not considered enough to justify the classification of the deposit as "orogenic". The facies of the diorite that formed the deposit and the pink granite dykes emplaced during the shear reactivation were not yet known in the Botuverá region.
\end{abstract}

Keywords: Geology of mineral deposit, Cavalo Branco (SC), gold, hydrothermalism, mineralogy.

INTRODUÇÃO A região de Botuverá (SC) tem sido garimpada para ouro e wolfrâmio desde os anos 70 (Lynn 1970 e Chaves \& Batola 1972 in Caldasso et al. 1995; Silva \& Krebs 1982; Silva et al. 1982). Cavalo Branco, Carneiro Branco, Braço Cristalino, Tigrano, Espinheiro, Ribeirão do Russo, Fanuelsson e Klaus (Fig. 1) são as principais ocorrências de ouro conhecidas. No Ribeirão do Russo, vários pequenos veios de quartzo com wolframita ocorrem próximos a veios com ouro e sulfetos de metais base. Cavalo Branco, Braço Cristalino e Ribeirão do Russo são as ocorrências de ouro mais importantes em dimensão e teor, contendo recursos estimados de cerca de 1.000 a $2.000 \mathrm{Kg}$ de
Au. Sondagem e estudos de viabilidade de lavra foram preparados pela AUROPAULA (Anos 80) e pela IVAI MINERAÇÃO (anos 90 e 2000), sem que, até hoje, tenha-se decidido pelo início dos trabalhos.

MÉTODOS As informações sobre a geologia regional (Fig. 1) foram obtidas da bibliografia e complementadas com informações provindas de perfilagens regionais feitas pelos autores, sobretudo visando obter indicadores cinemáticos das zonas de cisalhamento e das falhas (Figs. 2 e 3). A geologia local é produto do mapeamento de detalhe (Fig. 5) apoiado em mapas topográficos com escala 1:10.000 e da descrição de teste- 


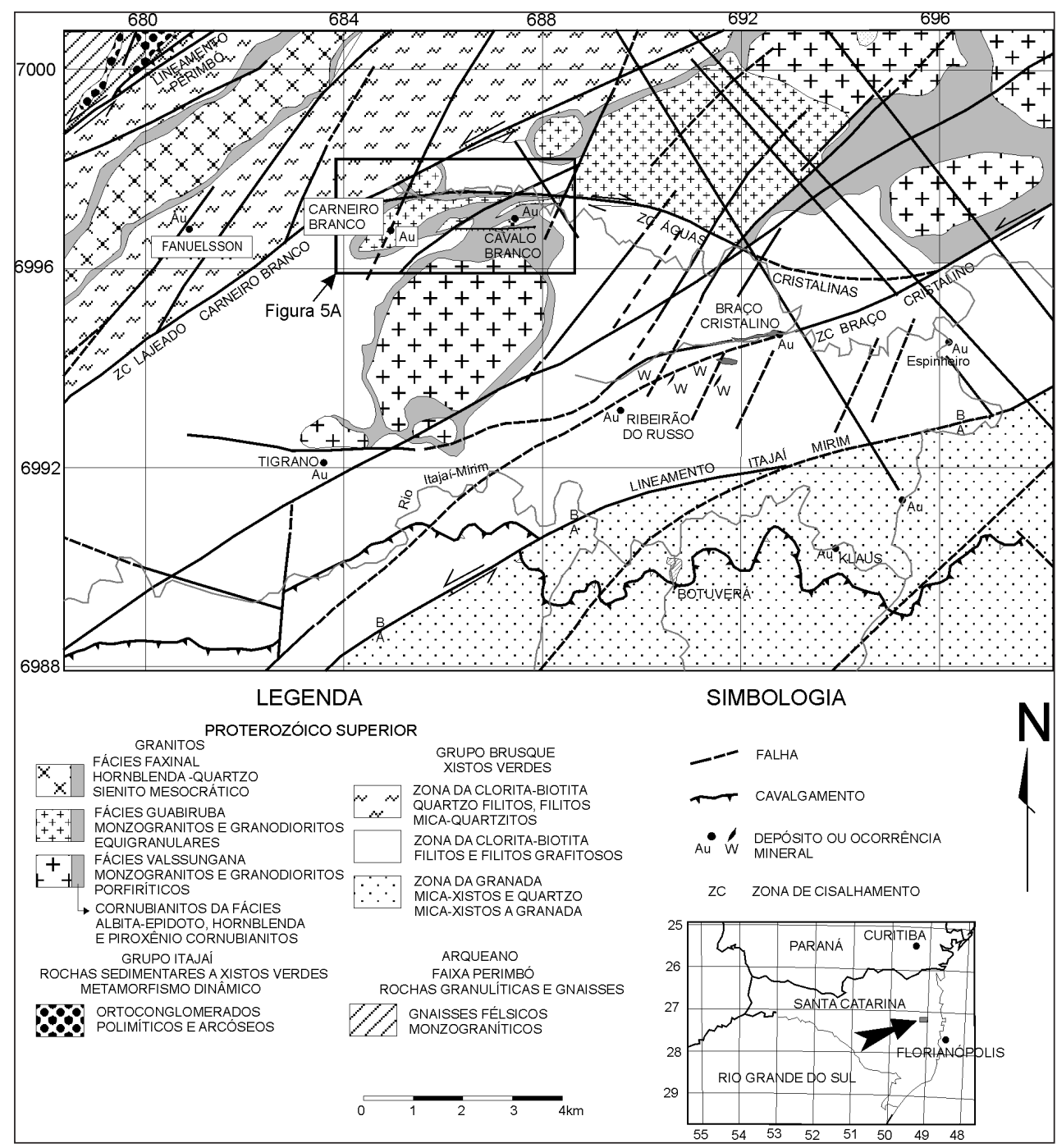

Figura 1 - Localização da área trabalhada, geologia da região de Botuverá (SC) e localização das principais ocorrências e garimpos de ouro e wolfrâmio (Modificado da Folha Botuverá, 1995, DNPM-CPRM, de Caldasso et al. 1995).

munhos de sondagem (Fig. 6).

Foram feitas lâminas delgadas e seções polidas com as amostras coletadas durante o mapeamento e a descrição de testemunhos de sondagem. As descrições das lâminas delgadas e seções polidas permitiu determinar as diversas paragêneses formadas durante a gênese do depósito e definir a sucessão paragenética das zonas de alteração hipogênica e do minério (Figs. 7 e 8). Da união das informações de campo, das sondagens e da petrografia foi deduzida a sucessão de eventos que resultaram na formação dos depósitos de ouro Cavalo e Carneiro Branco (Fig. 7).

Os minerais transparentes do minério e das rochas hidrotermalizadas do depósito Cavalo Branco foram analisados com uma microssonda eletrônica CAMECA SX-50 do Instituto de Geociências da Universidade de Brasília, calibrada e com os parâmetros seguintes: Aceleração do feixe de elétrons de $2 \pm 0,1 \mu \mathrm{A}$, tensão de $15 \mathrm{kV}$ e diâmetro de feixe de $10 \eta \mathrm{m}$ para feldspatos e de $5 \mathrm{\eta m}$ para os outros minerais. Foram utilizados os padrões fornecidos pela CAMECA. As proporções catiônicas e a elaboração de diagramas de classificação e composicionais foram calculadas e desenhadas com os "softwares" MINPET 2.02 e EXCEL 2000 (Figs. 9 a 13 e Tabs. 1 a 5). As condições de cálculo para cada mineral foram:

(a) Feldspatos: Oxigênio e $\mathrm{OH}(\mathrm{O}, \mathrm{OH}, \mathrm{F})=32$; $\mathrm{Al}_{\mathrm{IV}}$ no sítio tetraédrico $=8$-Si. Cátions normalizados para $\mathrm{Si}+\mathrm{Al}=16,0$;

(b) Anfibólio cálcico: Cálculo de $\mathrm{Fe}^{3+}$ pela média dos processos 15-NK e 13 CNK (Leake et al. 1997);

(c) Biotita: Oxigênio e $\mathrm{OH}(\mathrm{O}, \mathrm{OH}, \mathrm{F})=24$ (22 oxigênios); número de grupos $\mathrm{OH}=2,0 ; \mathrm{Al}_{\mathrm{IV}}$ no sítio tetraédrico $=8-\mathrm{Si}$. Cátions normalizados $\mathrm{Si}+\mathrm{Al}_{\mathrm{IV}}+\mathrm{Al}_{\mathrm{VI}}+\mathrm{Ti}+\mathrm{Cr}+\mathrm{Fe}^{2+}+\mathrm{Mn}+\mathrm{Mg}=14$

(d) Clorita: Oxigênio e $\mathrm{OH}(\mathrm{O}, \mathrm{OH}, \mathrm{F})=36$ (20 oxigênios); número de grupos $\mathrm{OH}=16$; $\mathrm{Al}_{\mathrm{IV}}$ no sítio tetraédrico $=8$-Si. Cátions normalizados para $\mathrm{Si}+\mathrm{Al}_{\mathrm{IV}}+\mathrm{Al}_{\mathrm{VI}}+\mathrm{Ti}+\mathrm{Cr}+\mathrm{Fe}^{2+}+\mathrm{Mn}+\mathrm{Mg}=20$

(e) Muscovita: Oxigênio e $\mathrm{OH}(\mathrm{O}, \mathrm{OH}, \mathrm{F})$ $=24$ (20 oxigênios); número de grupos $\mathrm{OH}=4 ; \mathrm{Al}^{\mathrm{IV}}$ 
no sítio tetraédrico $=8$-Si. Cátions normalizados para $\mathrm{Si}+\mathrm{Al}_{\mathrm{IV}}+\mathrm{Al}_{\mathrm{VI}}+\mathrm{Ti}+\mathrm{Cr}+\mathrm{Fe}^{2+}+\mathrm{Mn}+\mathrm{Mg}=14$.

Os minerais metálicos do minério do depósito de ouro Cavalo Branco também foram analisados com a microssonda eletrônica CAMECA SX-50 do Instituto de Geociências da Universidade de Brasília, calibrada e com os parâmetros seguintes: Voltagem de $20 \mathrm{KV}$ e amperagem de $40 \eta \mathrm{A}$. Para analisar ouro o tempo de contagem foi de 70 segundos, de 30 segundos para a prata e 10 segundos para os demais elementos metálicos (Figs. 14 e 15 e Tab. 6). Foram utilizados os padrões fornecidos pela CAMECA.

\section{GEOLOGIA REGIONAL}

Ambiente geotectônico A parte do escudo sul-brasileiro que aflora desde o estado de São Paulo até o Rio Grande do Sul, teve uma evolução complexa desde o Arqueano até o Ordoviciano. A geologia atual é conseqüência de várias orogenias associadas a sucessivas aberturas e fechamentos de oceanos, que resultaram em vários eventos de acreção e colisão continentais (Basei 1985, 2000, Machado et al. 1990, Chemale et al. 1995, Babinski et al. 1996, 1997, Hartmann et al. 1998, 1999a, 1999b, Leite et al. 1998, Silva et al. 1999, 2006, Remus et al. 1999, 2000a e 2000b). Datações SHRIMP $\mathrm{U}-\mathrm{Pb}$ em zircões confirmaram a presença de granulitos arqueanos no complexo Santa Maria Chico (RS), associados a uma acreção ocorrida há cerca de 2600 $\mathrm{Ma}\left(\mathrm{Sm}-\mathrm{Nd} \mathrm{T}_{\mathrm{DM}}\right.$, Hartmann 1998). A idade dos zircões magmáticos do complexo granulítico de Santa Catarina é $2716 \pm 17 \mathrm{Ma}$ e a dos zircões metamórficos é $2675 \pm 12$ Ma (Hartmann et al. 2000), portanto uma crosta arqueana (Ciclo Jequié) existiu no sul do Brasil, mas ela foi intensamente retrabalhada por eventos posteriores.

O Complexo Encantadas (RS) é testemunho de uma orogênese acrecionária transamazônica ocorrida há 2263 Ma (Hartmann et al. 2000), identificada nos gnaisses de Presidente Nereu, em Santa Catarina, com $2201 \pm 7 \mathrm{Ma}$, e na deformação dos granulitos catarineneses, há $2168 \pm 18 \mathrm{Ma}$ (Silva et al. 2000). Nessa orogênese houve um intenso magmatismo granítico potássico na região de Camboriú (SC) há $2006 \pm 3 \mathrm{Ma}$ (Silva et al. 2000) e em Encantadas (RS) há $2078 \pm 13$ Ma.

Não há evidências geocronológicas de orogêneses mesoproterozóicas (Uruaçuano ou Greenviliano) no sul do Brasil. Provavelmente esse foi o período de erosão das regiões elevadas e sedimentação do Grupo Brusque (SC), no qual, posteriormente, formaram-se os depósitos de ouro e wolfrâmio.

Ao menos três orogêneses brasilianas foram identificadas na região (Hartmann et al. 2000). A orogênese neoproterozóica mais antiga foi a Passinho ( $879 \pm 14 \mathrm{Ma})$, identificada nos metadioritos do complexo Cambai (Leite et al. 1998) e em rochas metassedimentares da região de Caçapava (Remus et al. 2000a). A orogênese acrecionária São Gabriel gerou grande quantidade de tonalito-trondhjemito-granodiorito no complexo Cambai, há $750 \pm 16 \mathrm{Ma}$, e ofiolitos há $733 \pm$ 10 (Leite et al. 1998). Há 698 \pm 16 Ma essas unidades foram empurradas para leste, sobre as rochas do crá- ton, ao mesmo tempo que formavam-se os depósitos de ouro da Bossoroca (Remus et al. 1999). Cerca de 100 Ma mais tarde a região sul brasileira foi atingida pela orogênese Dom Feliciano (Babinski et al. 1996, 1997; Leite et al. 1998; Silva et al. 1999), a mais importante do ciclo Brasiliano. As unidades por ela afetadas foram empurradas para oeste (Fig. 1) e houve fusão da crosta, gerando grande quantidade de granitos potássicos que constituem os batólitos Pelotas (RS) e Florianópolis (SC). Há vários remanescentes de bacias pós-tectônicas relacionadas a esta orogenia, a exemplo de Camaquã (RS) onde traquiandesitos, basais, datam $590 \mathrm{Ma}$ e basaltos toléíticos, do topo, datam $470 \mathrm{Ma}$ (Remus et al. 2000b). Nesta época, há 594 \pm 5 Ma formaram-se depósitos hidrotermais de $\mathrm{Cu}$ e/ou Au em Lavras e Camaquã (Remus et al. 2000b). Provavelmente durante esta orogênese formaram-se, também, os depósitos de ouro da região de Botuverá (Fig. 1).

\section{Geologia da região de Botuverá (SC)}

DOMINIOS LITOLÓGICOS Na região de Botuverá afloram rochas de quatro domínios geológicos (Fig. 1).

(1) Grupo Brusque - Formado por rochas metavulcano-sedimentares, com contribuição vulcânica subordinada, metamorfisadas na fácie xisto verde. Há três unidades distintas: (a) Faixa NW, limitada pelas zonas de cisalhamento Perimbó (a NW) e Lajeado Carneiro Branco (a SE), na qual predominam filitos quartzosos e filitos micáceo (facies xisto verde, zona da cloritabiotita). Nesta faixa está o garimpo de ouro Fanuelson. (b) Faixa central, limitada pelas zonas de cisalhamento Lajeado Carneiro Branco (a NW) e pelo lineamento Itajaí-Mirim (a SE), com filitos e filitos grafitosos também metamorfisados na fácies xisto verde, zona da clorita-biotita. Nesta faixa estão situados os depósitos de ouro Cavalo e Carneiro Branco, Braço Cristalino, Tigrano, Espinheiro e Ribeirão do Russo (com $\mathrm{W}+\mathrm{Au}$ ). (c) O lineamento Itají-Mirim separa os filitos, da faixa central, dos xistos a mica+quartzo e granada da faixa SE (fácies xisto verde, zona da granada). Nesta faixa está o garimpo de ouro Klaus.

(2) Rochas graníticas - Há três suítes distintas, todas do Neoproterozoico: (a) Fácies Valsungana, composta por monzogranitos e granodioritos porfiríticos. É desta suíte a maior parte dos granitos que afloram na área. (b) Fácies Guabiruba, composta por monzogranitos e granodioritos equigranulares. Os granitos Valsungana e Guabiruba são sin- a tardi- transcorrentes, metaluminosos a peraluminosos, tipo "S" e calcioalcalinos (Caldasso et al. 1995; Castro 1997). (c) Fácies Faxinal, composta por hornblenda-quartzo sienitos mesocráticos. São ganitos epizonais, metaluminosos, alcalinos, tipo "A" e provavelmente correspondem à última fase de granitização, ocorrida na área durante o Brasiliano. Todos os granitos geraram extensas auréolas termometamórficas, com cornubianitos de graus variados desde a fácies albita-epidoto até a fácies piroxênio-hornfels.

(3) No extremo NW da folha Botuverá afloram granulitos e gnaisses félsicos arqueanos da faixa Perimbó, limitada, a SE, pelo Lineamento Perimbó e, 
(4) Conglomerados polimíticos e arcóseos do Grupo Itajaí, alojados em bacias extensionais associadas a uma tectônica transcorrente, formadas sobre as rochas arqueanas.

GEOLOGIA ESTRUTURAL REGIONAL As múltiplas orogêneses que afetaram a região sul do Brasil geraram um padrão estrutural policíclico, caracterizado por reativações de estruturas antigas e gênese de novas estruturas. A fase mais antiga afetou somente o embasamento granulítico. A foliação milonítica dos granulitos foi totalmente transposta por foliações miloníticas de fases subseqüentes. As estruturas dos granulitos não influenciaram a formação dos depósitos de $\mathrm{Au}$ ou de W-Au da região de Botuverá.

Duas fases de tectônica tangencial, D1 e D2, afetaram rochas do Grupo Brusque. A essas fases associam-se as várias de zonas de cisalhamento de baixo e médio ângulos, geradas e/ou reativadas durante a orogênese Dom Feliciano. Estas deformações são responsáveis pela gênese das foliações de transposição $\mathrm{S} 1$ e $\mathrm{S} 2$, restritas às rochas do Grupo Brusque. Estas foliações são plano-axiais de dobras isoclinais recumbentes, possivelmente associadas a "nappes" (Caldasso et al., 1995, p. 194). A foliação S1 é discreta e descontínua, lenticularizada, paralela ao bandamento composicional rítmico, areno-pelítico. A S2 ocorre em graus variados, desde uma clivagem de crenulação até uma forte xistosidade plano axial de dobras com planos axiais ondulados e sub-horizontais. A atitude dessa foliação muda constantemente em função da proximidade das intrusões graníticas e de zonas de cisalhamento. S2 é a foliação que mais se destaca nos filitos e xistos da região de Botuverá.

Após preenchida, a bacia do Itajaí foi deformada pelas fases transcorrentes D3 e D4. Foram gerados cavalgamentos E-W que superpuseram xistos da faixa SE do Grupo Brusque aos filitos da faixa central e deformaram rochas da borda SE da Bacia do Itajaí (Caldasso et al. 1995). A fase D3 gerou uma clivagem de fratura, praticamente inexistente na região de Botuverá. A fase D4 está impressa nas rochas sedimentares do Itajaí e nos metamorfitos do Grupo Brusque sob a forma de flexuras monoclinais com variações do tipo "chevron". A esta fase associa-se uma clivagem de crenulação, algumas vezes excepcionalmente desenvolvida nos metapelitos ao ponto de mascarar, localmente, a S2.

Na região dos depósitos de Au Cavalo e Carneiro Branco, a zona de cisalhamento Lajeado Carneiro Branco (Fig. 1) é levógira, com atitude geral $\mathrm{N} 82^{\circ} \mathrm{E}$, Vertical. A zona de cisalhamento Águas Cristalinas é curva, dextrógira e, provavelmente, conjugada à Lajeado Carneiro Branco. Mais a SE, a zona de cisalhamento Braço Cristalino é levógira, com atitude geral $\mathrm{N} 75-85^{\circ} \mathrm{E}, 86^{\circ} \mathrm{NW}$. A ela associam-se os depósitos de Au Braço Cristalino, Tigrano e Ribeirão do Russo, com W-Au.

Os lineamentos Perimbó e Itajaí-Mirim são falhas trancorrentes levógiras com estruturas transtensivas e transpressivas associadas. São notáveis pelo desenvolvimento de zonas de brecha sobre milonitos mais antigos. O lineamento Itajaí-Mirim causou um alçamento de bloco que colocou em contato rochas de diferentes graus metamórficos. Estas falhas não interferiram diretamente na formação dos depósitos de $\mathrm{Au}$ e W da região

INFLUENCIA DAS ESTRUTURAS SOBRE AS MINERALIZAÇÕES Cavalo e Carneiro Branco, Tigrano, Fanuelson, Braço Cristalino e Ribeirão do Russo são, todos, depósitos filoneanos de $\mathrm{Au}$ e/ou $\mathrm{Au}+\mathrm{W}$ em quartzo, associados a zonas de cisalhamento, sempre situados no interior ou muito próximo de plutões graníticos. Os corpos mineralizados desses depósitos têm formas e atitudes variadas: (a) $\mathrm{O}$ veio de quartzo mineralizado estava boudinado e segmentado em sigmóides quando houve interferências entre a foliação milonítica S2, regional, e a foliação de cisalhamento no local do depósito. É o que ocorre na cava do Davi (Figs. 4, 5B e 6). (b) Quando o veio de quartzo está fora da zona de cisalhamento, o quartzo é maciço, branco leitoso e não tem evidências de deformação. O melhor exemplo é o minério da Cava Leste (Figs. 5B e 6B e C) e o veio do Carneiro Branco.

Embora seja desconhecida a seqüência de formação das zonas de cisalhamento e quantas reativações tiveram, causadas pelas diversas orogêneses que afetaram a região, as principais características morfológicas e composicionais dos depósitos foram herdadas da orogênese Dom Feliciano.

Cavalo e Carneiro Branco e, possivelmente, Fanuelson, são conjuntos de filões cujas localizações e atitudes estão condicionadas pela zona de cisalhamento Lajeado Carneiro Branco (Fig. 1). A parte cisalhada do filão Cavalo Branco é muito descontínua, com quartzo boudinado e tem atitude média EW, 35-60 ${ }^{\circ} \mathrm{S}$ (Figs. $2 \mathrm{~A}$ e $\mathrm{B})$, diferente do Carneiro Branco, um filão maciço, com atitude média $\mathrm{N} 17^{\circ} \mathrm{W}, 74 \mathrm{NE}$ (Figs. 2A e B).

Cristalino, Ribeirão do Russo e Tigrano são filões controlados pela zona de cisalhamento Braço Cristalino (Fig. 1). Os veios de quartzo do Braço Cristalino têm atitude média $\mathrm{N} 82^{\circ} \mathrm{E}, 86^{\circ} \mathrm{NW}$ (Figs. 2D e E), embora os mergulhos oscilem bastante, entre NW e SE (Fig. 2G). No Ribeirão do Russo os veios de quartzo com wolframita são sub-verticais, com direções N20 $30^{\circ} \mathrm{E}$ (Fig. 1).

\section{GEOLOGIA DOS DEPÓSITOS DE OURO CAVA- LO E CARNEIRO BRANCO}

Contexto geológico do depósito Pouco mais da metade do veio de quartzo aurífero Cavalo Branco está boudinado, alojado em uma zona de cisalhamento EW que secciona o diorito Cavalo Branco. A parte mineralizada não deformada está fora da zona de cisalhamento e dentro de diorito e de filito Brusque regional (Fig. 6). Todo o veio de quartzo e o diorito encaixante estão em meio a cornubianitos gerados por granitos das fácies Valsungana, a sul, e Guabiruba, a norte (Fig. 5A). O veio de quartzo Cavalo Branco aflora de modo descontínuo por cerca de 300 metros, com espessura variando 


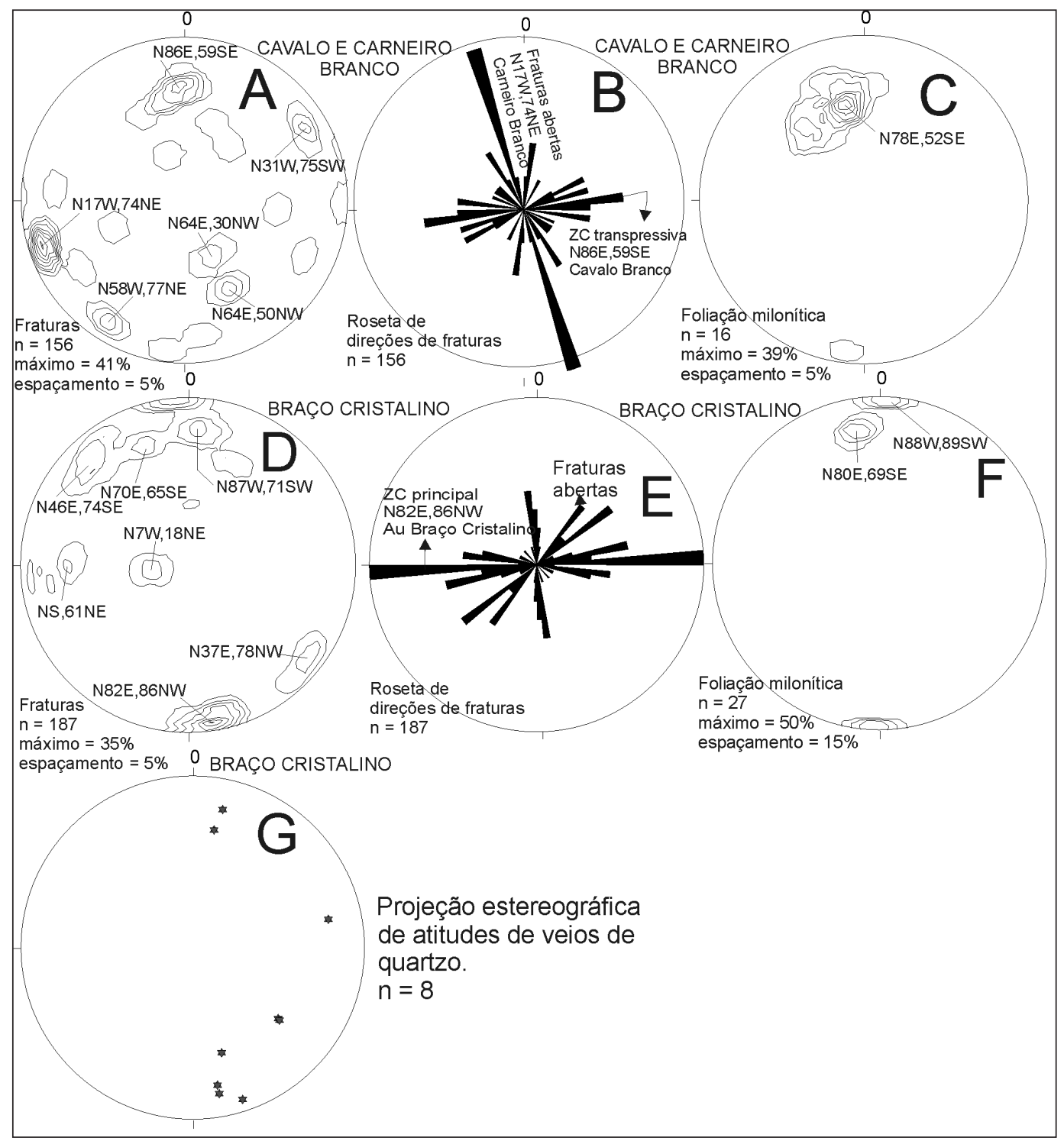

Figura 2 - Diagramas estruturais da região dos depósitos Cavalo e Carneiro Branco. $A-B-C$-Diagramas de freqüência e de projeção de atitudes de juntas e foliações medidas na região dos depósitos de ouro Cavalo e Carneiro Branco. D-E-F-G - Diagramas de freqüencia e de projeção de atitudes de fraturas, foliações e veios de quartzo medidas na região do depósito de ouro do Braço Cristalino. A variação das atitudes dos veios de quartzo é conseqüencia do fatiamento e arqueamento causados por reativações do cisalhamento. Projeção estereográfica no hemisfério inferior.

entre 0,1 e 3,0 $\mathrm{m}$ e atitude EW, $35^{\circ}-60^{\circ} \mathrm{S}$ (Fig. 5B). Na Cava do Davi (Fig. 5B), dentro do diorito cisalhado, os teores em ouro variam de 4 a $40 \mathrm{~g} /$ ton, enquanto na parte externa do diorito os teores diminuem para menos de $10 \mathrm{~g} /$ ton. O mapeamento de superfície, feito com o auxílio de trincheiras, das frentes de lavra e cinco sondagens rotativas (F4, F9, F9A, F10 e F12A, nas Figs. 5B e 6), permitiram definir a distribuição das rochas e coletar amostras a profundidades de até 90 metros abaixo da superfície.

O diorito está encaixado em cornubianitos pelíticos com os quais tem contatos verticais a sub-verticais (Figs. 5B e 6A). O cisalhamento local corta o granito transversalmente, ora aflorando dentro do diorito (Cava do Davi, Fig. 6A) ora dentro dos cornubianitos (Cava
Leste, Fig. 5B). Dentro do diorito há uma zona com muitos xenólitos de anfibolito e, menos freqüentes, de cornubianito (Figs. 6A, B e C). As sondagens revelaram a presença de muitas vênulas e diques de granito róseo com espessuras centimétricas a decimétricas, com granulometria grossa, hidrotermalmente alterados, que cortam o diorito, os cornubianitos e o veio de quartzo mineralizado. Este granito é claramente posterior ao diorito e à mineralização.

O Carneiro Branco é um veio de quartzo maciço, com muita pirita, com cerca de 0,5 metro de espessura média e comprimento em superfície menor que 50 metros. Está contido em uma fratura extensional N20 $30^{\circ} \mathrm{W}$, vertical, conjugada a um cisalhamento $\mathrm{N} 5^{\circ}-20^{\circ} \mathrm{E}$, vertical (Fig. 5A), que afloram em meio a granito da 


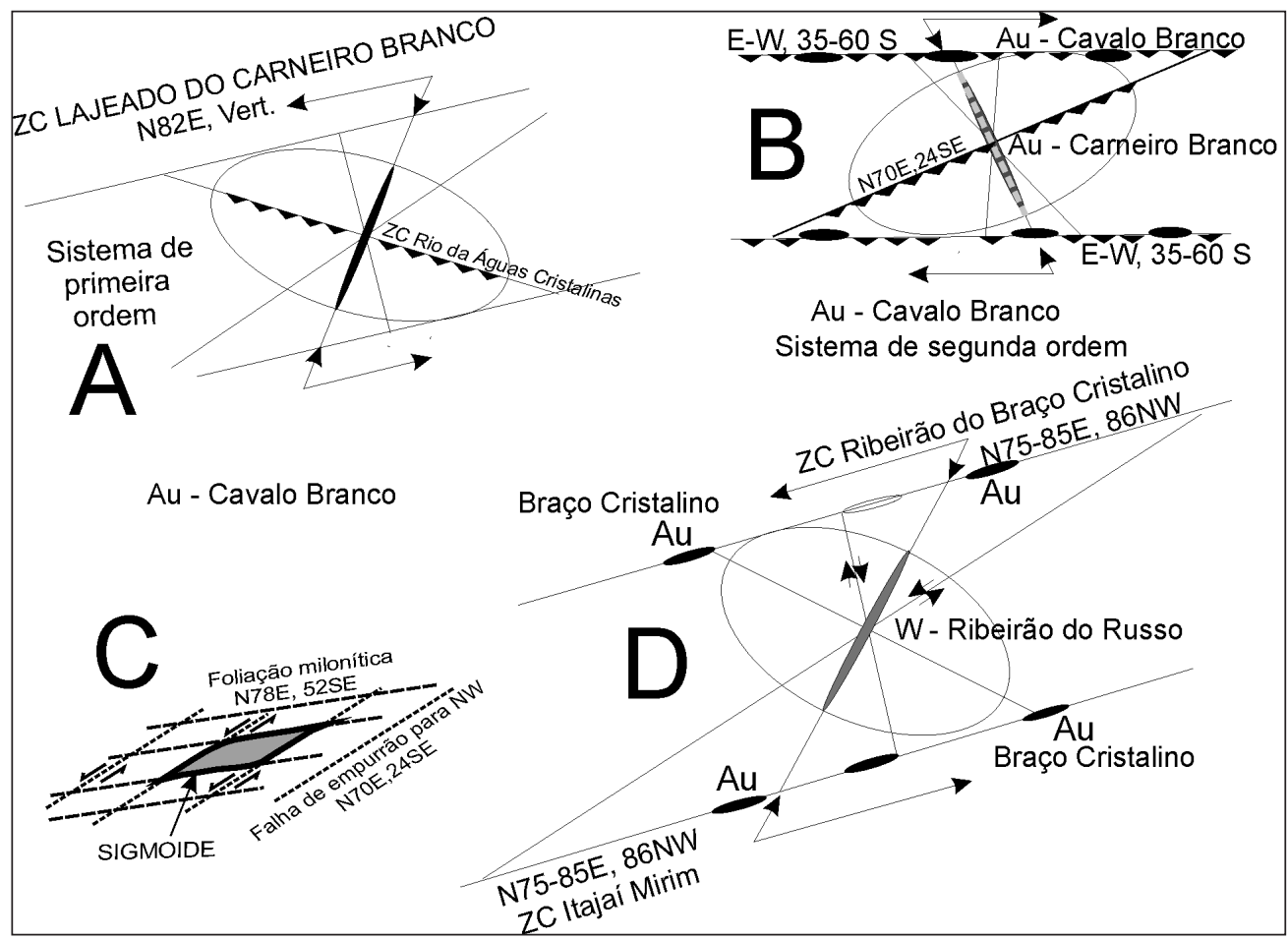

Figura 3 - Origem das fraturas e deformações observadas em rochas associadas aos depósitos Cavalo e Carneiro Branco. (A) Elipsóide de deformação das fraturas conjugadas à zona de cisalhamento Lajeado do Carneiro Branco. (B) Elipsóide de deformação do conjunto das fraturas conjugadas à zona de cisalhamento Águas Cristalinas, onde se encontram os depósitos de Au Cavalo e Carneiro Branco. (C) Esquema que mostra a origem da boudinage do veio de quartzo Cavalo Branco. (D) Elipsóide de deformação das fraturas conjugadas à zona de cisalhamento Ribeirão do Braço Cristalino, onde estão os depósitos de Au Cristalino e de W Ribeirão do Russo.

fácies Guabiruba. Este veio foi lavrado apenas em superfície e, embora os teores sejam maiores que os do Cavalo Branco, não foi sondado.

Transformações das rochas ocorridas durante a gênese dos depósitos de ouro Cavalo e Carneiro Branco

A SUCESSÃO MINERALÓGICA HIDROTERMAL O diorito Cavalo Branco alojou-se entre cornubianitos formados pelas intrusões dos granitos Lajeado do Botuverá (fácies Valsungana) e Santo Antônio (fácies Guabiruba), provavelmente preenchendo uma fratura conjugada à zona de cisalhamento Rio das Águas Cristalinas. Os cornubianitos encaixantes são rochas formadas pela enésima geração (Fig. 7) de quartzo, muscovita, biotita, andaluzita, plagioclásio, silimanita e cloritóide, produto do termometamorfismo de metapelitos e xistos do Grupo Brusque. Em meio a essas rochas, o magma granítico cristalizou apatita, esfeno, alanita, biotita (Biot1), quartzo (Qzo1), hornblenda, magnetita (Mgta1), feldspato K (Fk1) e plagioclásio (Plagio1). Esse magma tinha excesso de água, o que causou alteração tardi-magmática do feldspato $\mathrm{K}$, que foi sericitizado (Mct1), da hornblenda e da biotita, que foram parcialmente cloritizadas (Clta1) e a cristalização de franjas de albita (Plagio2) em torno do felsdspato sericitizado (Figs. 7, 8A). Finda a alteração tardi-magmática come- çou o hidrotermalismo, causado por fluídos que subiram via fratura que transgride os limites do granito e se estende até as encaixantes. Esta fratura foi preenchida por quartzo (Qzo2) e mineralizada com muito pouco sulfeto e ouro. Concomitantemente, granito e cornubianito encaixantes do veio de quartzo foram alterados pelos fluídos hidrotermais.

No início do hidrotemalismo, em ambiente com temperatura provavelmente elevada, cristalizaram-se microclínio (Fk2, Figs. 7, 8A) e biotita (Biot2, Figs. 7, 8B), junto à turmalina e espinélio (Fig. $8 \mathrm{C}$ ), caracterizando uma zona potássica que faz uma auréola irregular e descontínua em torno do veio de quartzo. Com a diminuição da temperatura, cristalizaram sericita (Mct2), magnetita (Mgta2) e quartzo (Qzo2), disseminados em uma zona fílica em torno da zona potássica. Durante a filitização cristalizaram pouca pirita (Py1), muito pouca calcopirita (Ccpy1) e traços de galena (Gal) e ouro (Au1), formando o minério primário. A primeira fase hidrotermal terminou com a cristalização de clorita 2 (Clt2, Fig. 7), disseminada, da clorita 3 (Clt3), nas clivagens dos fenoblastos de muscovita dos cornubianitos (Figs. 8D) e de epidoto (Ept2) disseminados, formando uma zona de alteração propilítica (Fig. 7). O aumento de temperatura causado pelo início de uma reativação termo-tectônica propiciou a disseminação de carbonato (Cabto1). 

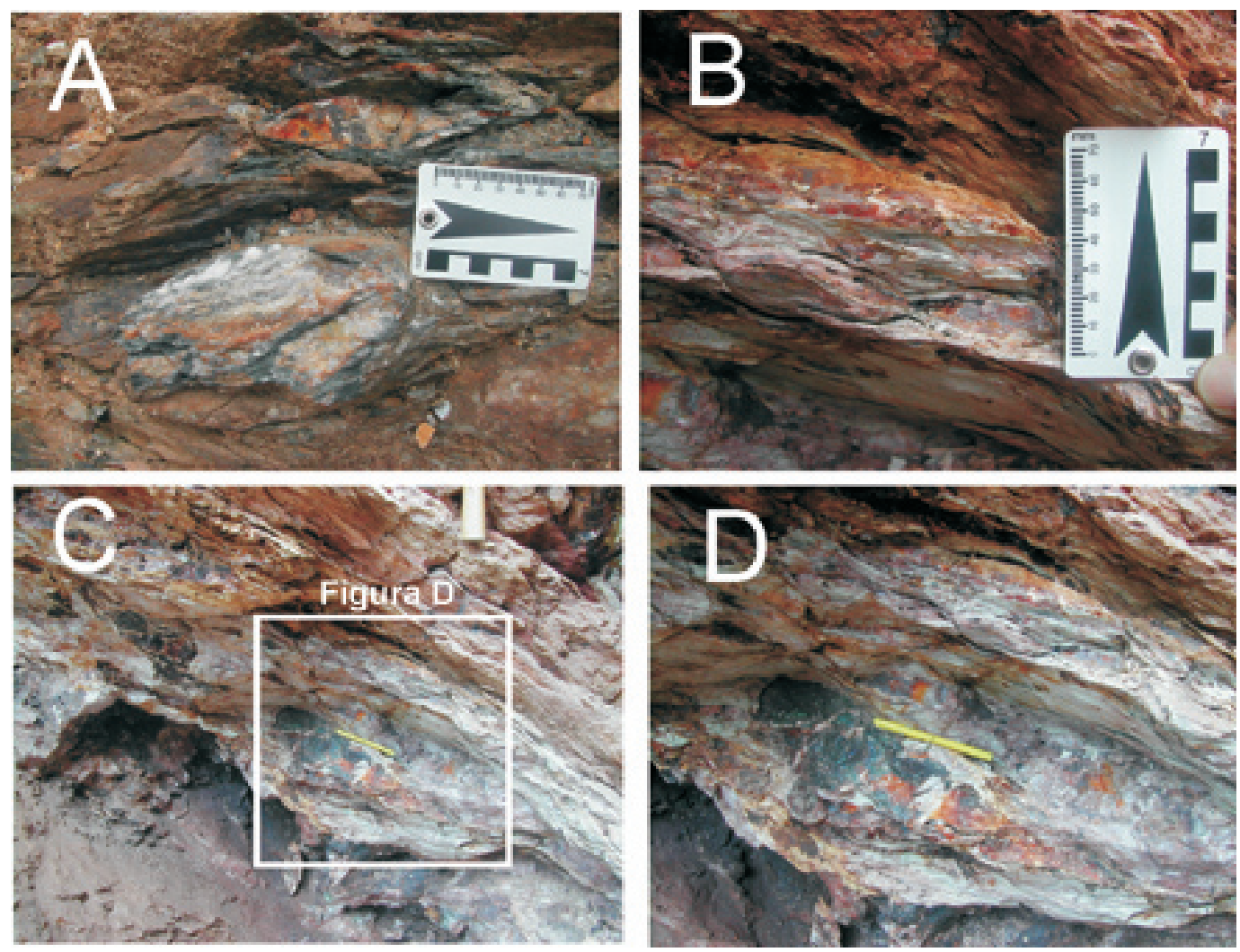

Figura 4 - "Boudins" de quartzo com Au do filão Cavalo Branco, formados em meio a pelitos do Grupo Brusque e ao diorito Cavalo Branco.

Formadas as zonas de alteração hidrotermal, houve reativação da zona de cisalhamento Lajeado do Carneiro Branco (Fig. 3A). Em um sistema de fraturas conjugadas de segunda ordem formou-se a zona de cisalhamento EW, $35^{\circ}-60^{\circ} \mathrm{S}$ (Fig. 3B) que seccionou o granito Cavalo Branco (Figs. 5B, 8E) e os cornubianitos. A reativação tectônica proporcionou a subida de veios e vênulas de magma granítico (Fig. 6) que iniciou uma segunda fase hidrotermal.

No início da reativação, em regime de temperatura crescente, nos locais onde a zona de cisalhamento de baixo ângulo (Fig. 5B) cruzou o veio de quartzo mineralizado, o quartzo foi boudinado (Qzo3, Fig. 7), segmentado em sigmóides (Figs. 3C e 4) e os minerais metálicos foram mobilizados mecanicamente. As zonas anteriormente hidrotermalizadas foram carbonatizadas (Cabto2, Fig. 7), com carbonato preenchendo uma rede de microfissuras e formando glomérulos. $\quad \mathrm{N}$ o vas soluções hidrotermais lixiviaram o potássio dos fenoblastos de muscovita (Mct2) dos cornubianitos encaixantes, transformando-os parcialmente em fibrolita (Figs. 7 e 8F), mas preservando o cloritóide (Fig.8H). Localmente a lixiviação foi completa, causando o desaparecimento da muscovita e a cristalização de quartzo (Qzo4, Fig. 7), que englobou a fibrolita (Fig. 8G).

Na fase final da reativação termo-tectônica, a diminuição da temperatura propiciou a silicificação geral das rochas (Qzo4, Fig. 7), proporcionando o englobamento da fibrolita pelo quartzo, a formação de glomérulos de clorita 4 (Figs. 80) nos locais próximos às vênulas de granito rosado e a disseminação de clorita 5 , tubular "vermiforme" (Fig. 8I), no diorito.

Durante a primeira fase hidrotermal, o ouro granular (Au1) cristalizou primeiro, dentro do quartzo (Qzo2), e posteriormente foi envolvido por pirita maciça (Py1, Fig. 8J). Muito pouca calcopirita (Ccpy1) e galena cristalizaram logo após a pirita. Na segunda fase hidrotermal, associada à intrusão de vênulas graníticas e ao cisalhamento do diorito e de parte do veio mineralizado, a pirita (py2) foi fraturada, cisalhada e parcialmente recristalizada (Fig. 8K), enquanto a calcopirita (Ccpy2) e o ouro foram mecanicamente mobilizados para microfraturas (Figs. 8L). Findo o hidrotermalismo, atingida por fluídos meteóricos a calcopirita alterou-se para calcosita, depois para covelita e óxidos de cobre, e a pirita transformou-se em ghoetita (Fig. 8M).

\section{A SUCESSÃO MINERALOGICA TERMOMETAMÓR-} FICA Os cornubianitos situados fora da zona hidrotermalizada foram recristalizados quando houve a intrusão do diorito Cavalo Branco e das vênulas de granito. Quartzo (Qzo $n+1)$, andaluzita (And $n+1)$ e novos fenoblastos de muscovita (Mct $n+2)$ cristalizaram em uma nova zona de fácies albita-epidoto que se superpôs a uma zona antiga da fácies hornblenda-hornfels (Fig. $8 \mathrm{~N}$ ). Novos fenoblastos de muscovita cristalizaram, também, no metapelito cisalhado. A recristalização da muscovita das antigas zonas da fácies albita-epidoto gerou muscovititos (Mct n+3) maciços, com granulometria grossa, que se assemelham a muscovita-greisens. 


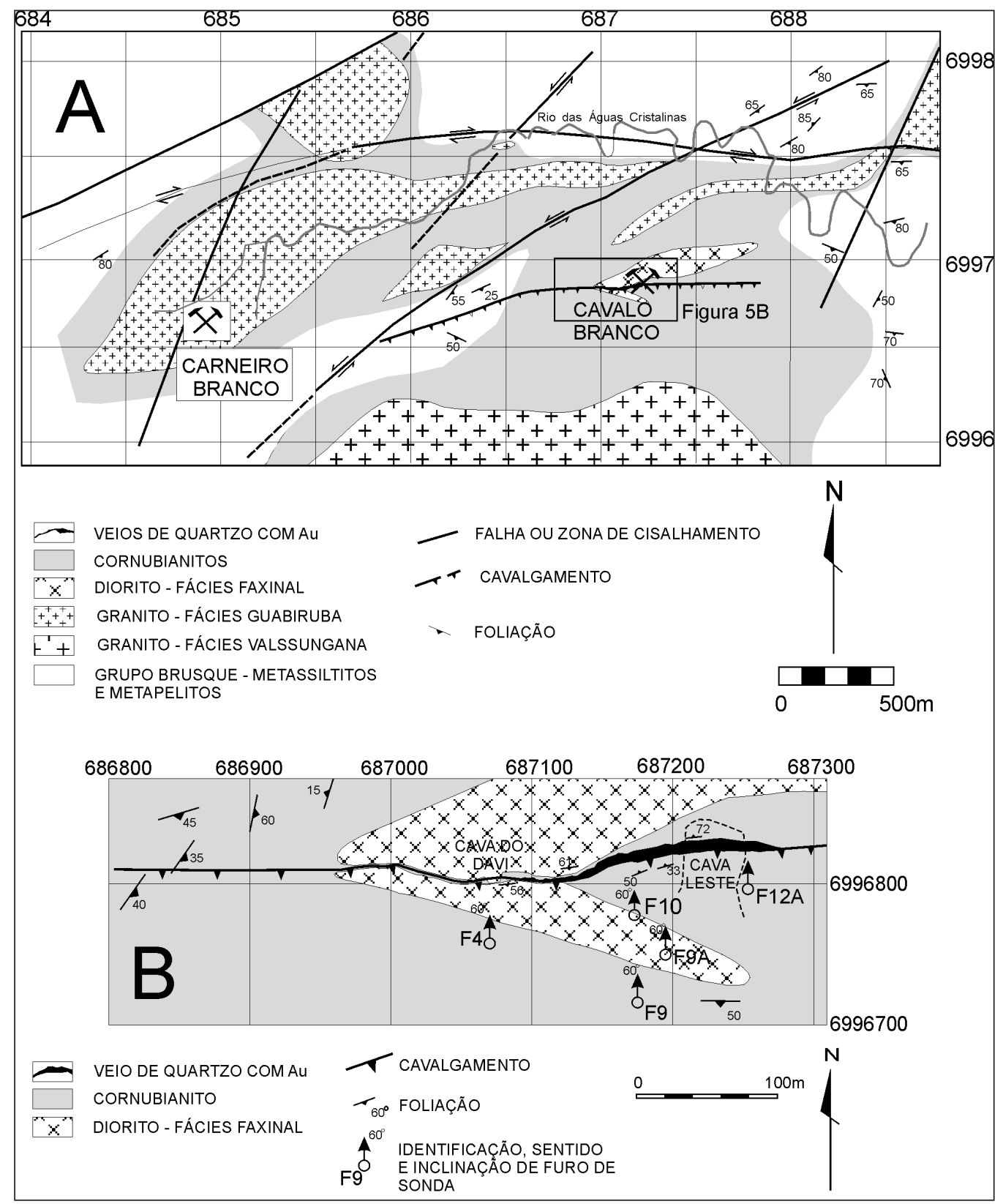

Figura 5 - Geologia regional e local do depósito Cavalo Branco. (A) Mapa geológico que localiza os depósitos do Cavalo e Carneiro Branco e o diorito Cavalo Branco em meio a cornubianitos. O retângulo do centro da figura corresponde à figura B. (B) Detalhe mostrando o veio de quartzo aurífero Cavalo Branco e a posição dos furos de sondagem feitos para pesquisá-lo em profundidade.

Características químicas dos minerais transparentes dos depósitos de ouro Cavalo e Carneiro Branco. ANFIBÓLIO O anfibólio (Anf1) do diorito é magnésio-hornblenda (Fig. 9, Tab. 1). Durante a fase de alteração tardi-magmática a parte externa dos cristais de hornblenda foi cloritizada (Clt1). Durante a terceira fase de alteração hidrotermal, a alteração propilítica, transformou alguns cristais de magnésio-hornblenda em actinolita-hornblenda e em actinolita (Anf2, Figs. 7 e 9). Na parte do depósito afetada pela zona de cisalhamento, na segunda fase hidrotermal, o anfibólio foi todo recristalizado em glomérulos de clorita (Clt4, Figs. 7, 80 e 13).
FELDSPATO O ortoclásio (Fk1) e o plagioclásio (Plagio1) do diorito foram sericitizados (Mcta1, Fig. 12) durante a alteração tardi-magmática (Fig. 7 e Tab. 2). O sódio e a sílica liberados por essa reação cristalizaram franjas de albita (Plagio2) em torno dos cristais de feldspato (Fk1) sericitizados (Fig. 8A). O cálcio e o potássio liberado do plagioclásio cristalizou epidoto (Ept1) + sericita (Mcta1), que substituíram o plagioclásio (Fig. 7). A albitização tardi-magmática dos feldspatos foi incompleta, conforme mostra a figura 10, onde cristais cujas composições situam-se no domínio do anortoclásio correspondentes a ortoclásios que não foram totalmente albitizados. Após a alteração tardi-magmática, 

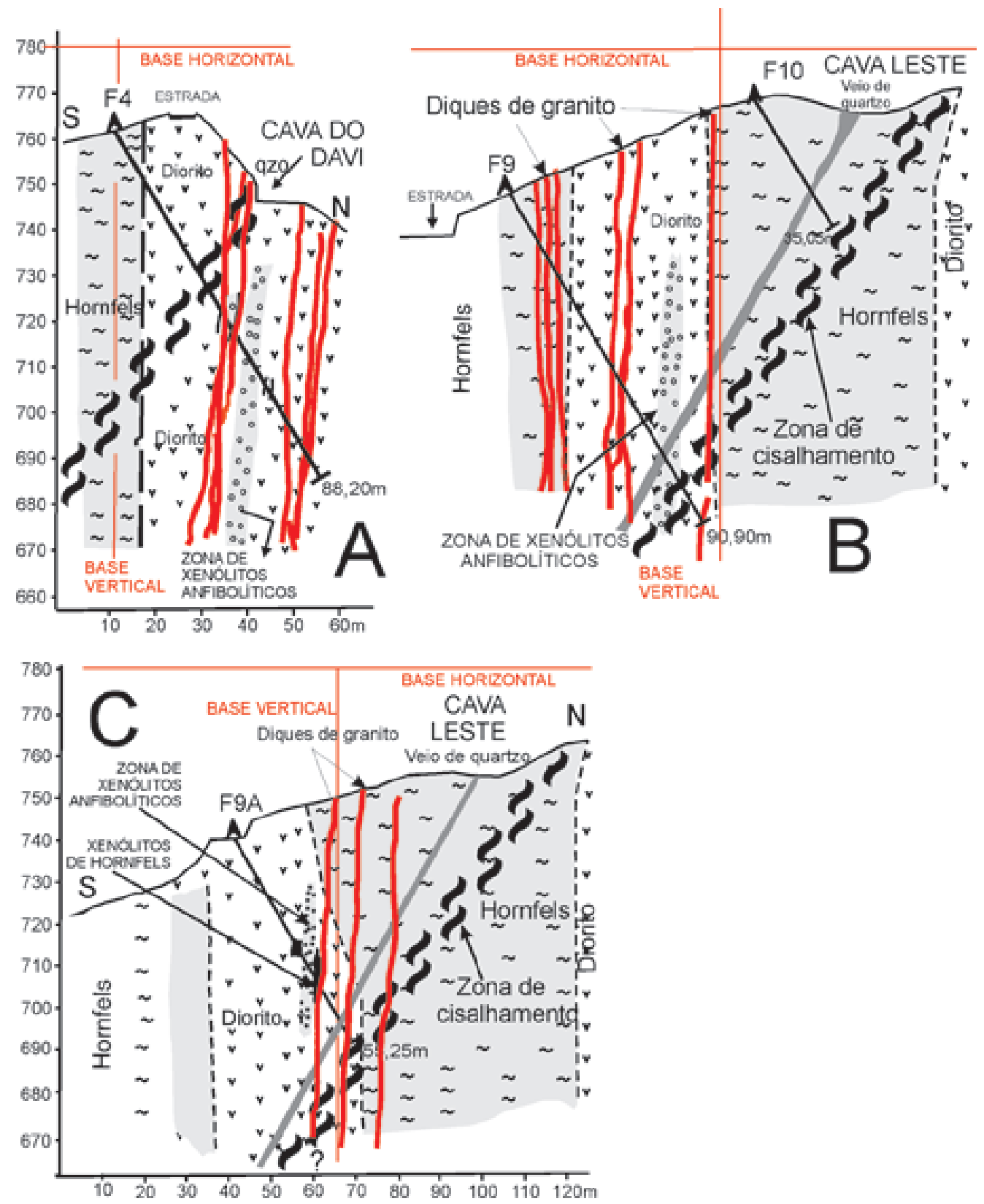

Figura 6 - Seções geológicas no veio do depósito Cavalo Branco (A, B e C) Notar que a zona de cisalhamento que contém parte do veio de quartzo secciona o diorito e o cornubianito encaixante. Notar, também, a presença de vênulas e diques de granito que seccionam todas as estruturas e rochas.

o início do hidrotermalismo proporcionou o aporte de sílica e de potássio, gerando uma zona potássica, caracterizada pela cristalização de biotita (Biot2), de microclínio (Fk2) e de muito pouca albita (Plagio3).

BIOTITA A biotita do diorito foi reequilibrada (Biot1) durante o hidrotermalismo potássico e transformada em biotita verde, secundária (Figs.11A e B e Tab. 3). Durante a propilitização (Fig. 7), localmente a biotita foi parcialmente recristalizadas em clorita, adquirindo estrutura cristalina e composição química intermediárias entre a da biotita e a da clorita (Fig. 11A, parte sombreada, com $\mathrm{Al}_{\mathrm{IV}}<2$ ).

MICA BRANCA A zona hidrotermal fílica formou-se após o hidrotermalismo potássico. A zona fílica desenvolveu-se nos locais onde o corpo mineralizado está encaixado em muscovita cornubianitos (Fig. 5B) e praticamente inexiste no diorito. Não há diferença composicional entre os fenoblastos de muscovita recristalizados durante a primeira fase de hidrotermalismo (Mct2), os fenoblastos estirados durante o cisalhamento (Mct3, Figs. 7 e $8 \mathrm{~V}$ ) e aqueles cristalizados durante a última fase de hidrotermalismo (Mct4, Fig.7). Todos são muscovita, levando a crer que apenas foram transformados mecanicamente sem incorrer em nenhuma mudança composicional (Fig. 12 e Tab. 4), embora venham a constituir paragêneses diferentes (Fig. 7).

A mineralização em ouro (Au1), pirita (Py1), 


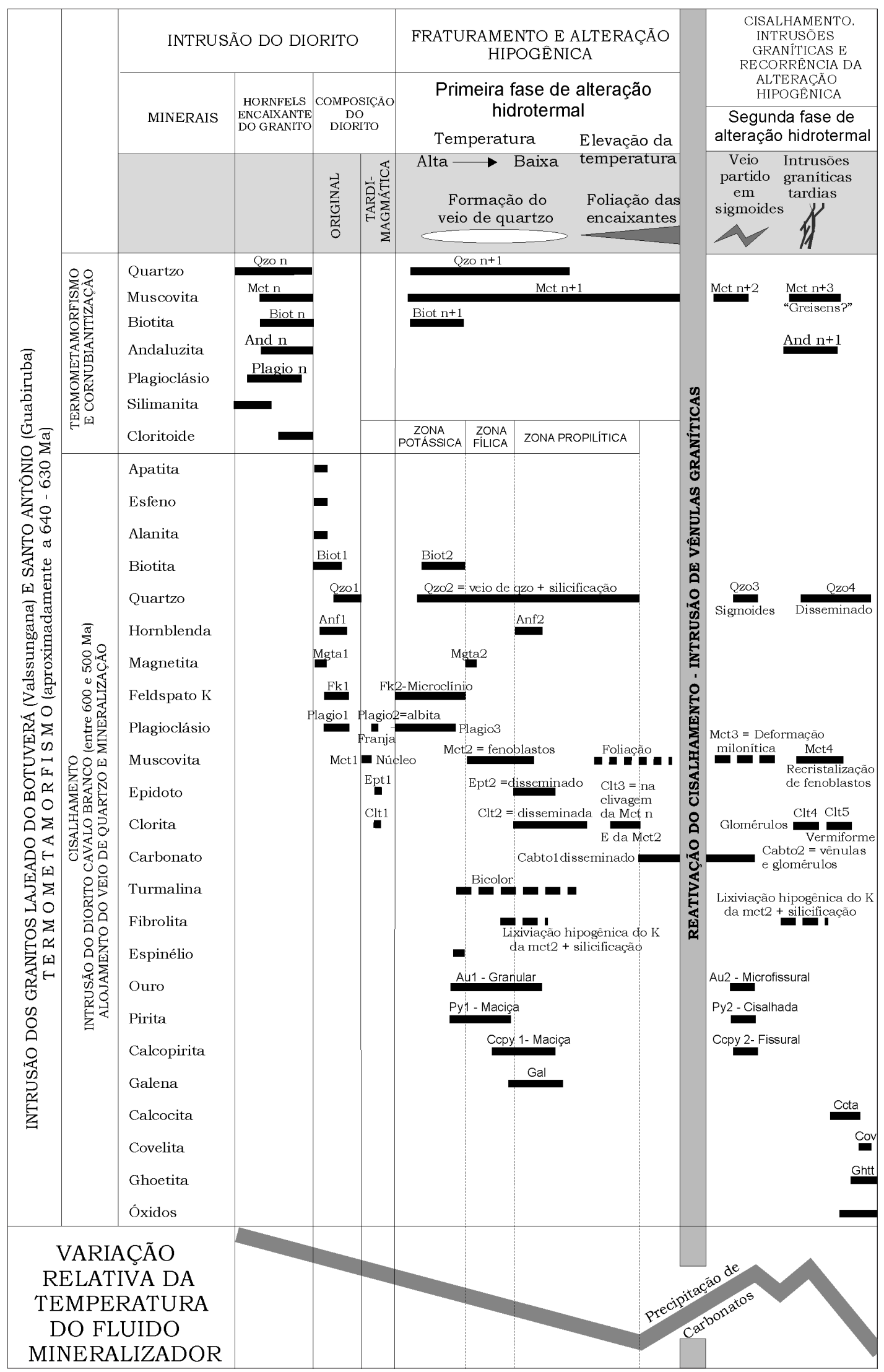

Figura 7 - Sucessão de eventos e sucessão paragenética hidrotermal ocorridos durante a gênese do depósito de ouro Cavalo Branco. Abreviações: Qzo = quartzo, Mct = muscovita ou sericita, Biot = biotita, And = andaluzita, Plagio = plagioclásio, Anf = anfibólio, Mgta $=$ magnetita, $F k=$ feldspato potássico (ortoclásio ou microclínio), Ept $=$ epidoto, $C l t=c l o-$ rita, Cabto = carbonato, Au =ouro, Py = pirita, Ccpy = calcopirita, Gal = galena, Ccta = Calcosita, Cov = covelita e Ghtt $=$ goethita . 

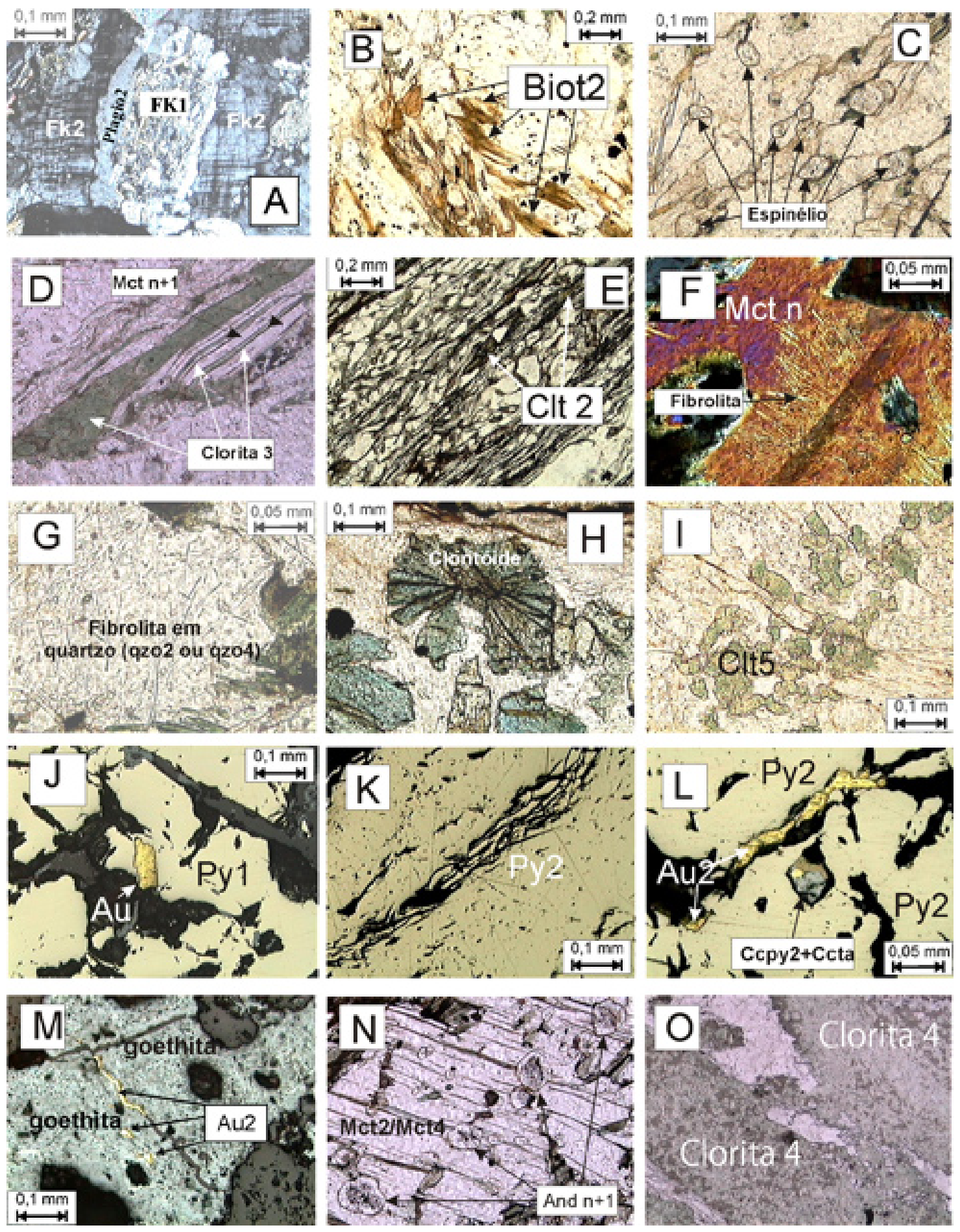

Figura 8 - Imagens de minerais cristalizados em rochas e minérios dos depósitos Cavalo e Carneiro Branco. Simbologia: $N C=$ nicóis cruzados, $N P=$ nicóis paralelos, $L F=l u z$ refletida. $(A): N C$ Fk1 transformado em sericita 1 (Mct1) durante alteração tardi-magmática envolvido por Fk2 da zona hidrotermal potássica. (B): NP-Biotita 2, hidrotermal, da zona potássica. (C):NP-Espinélio hidrotermal. (D):NP-Clorita hidrotermal (Clt3) nas clivagens de muscovita termometamórfica

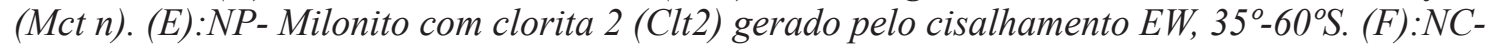
Fibrolita (silimanita) dentro de fenoblasto de muscovita termometamórfica (Mct n). (G):NP-Fibrolita dentro de quartzo hidrotermal (Qzo2 ou Qzo 4). (H):NP-Cloritoide em rocha com fibrolita. (I):NP:Clorita 5 (Clt5), "vermiforme"ou "tubular".(J):NP, luz refletida-Ouro granular (Au1) dentro de pirita (Py1). (K):NP, luz refletida-Pirita cisalhada (Py2). (L):NP, luz refletida-Ouro (Au2) e calcopirita (Cсру2) remobilizados após o cisalhamento. (M):NP, luz refletida-Ouro recristalizado (Au2) dentro de pirita goethitizada. (N):NP-muscovita hidrotermal (Mct2 ou Mct4) com inclusões de andaluzita termometamórfica $($ And $n+1)$ recristalizada. $(O)$ :NC-Fenoblasto de muscovita (Mct4) formado na segunda fase hidrotermal. 
Tabela 1 - Análises químicas de anfibólio dos depósitos Cavalo e Carneiro Branco

\begin{tabular}{|c|c|c|c|c|c|c|c|c|c|c|c|c|c|}
\hline Amostra & $\begin{array}{c}\text { L1-P9 } \\
8\end{array}$ & $\begin{array}{c}\text { L1-P8 } \\
1\end{array}$ & $\begin{array}{c}\text { L1-P8 } \\
3\end{array}$ & $\begin{array}{c}\text { L1-P8 } \\
4\end{array}$ & $\begin{array}{c}\text { L1-P4 } \\
1\end{array}$ & $\begin{array}{c}\text { L1-P4 } \\
2\end{array}$ & $\begin{array}{c}\text { L1-P3 } \\
5\end{array}$ & $\begin{array}{c}\text { L1-P3 } \\
7\end{array}$ & $\begin{array}{c}\text { L1- } \\
\text { P10 } \\
1\end{array}$ & $\begin{array}{c}\text { L1- } \\
\text { P10 } \\
6\end{array}$ & $\begin{array}{c}\text { L1- } \\
\text { P10 } \\
7\end{array}$ & Média & $\begin{array}{l}\text { Desv. } \\
\text { Padrão }\end{array}$ \\
\hline $\mathrm{SiO}_{2}$ & 44,55 & 56,29 & 45,90 & 52,03 & 44,20 & 44,51 & 46,34 & 45,43 & 43,89 & 45,06 & 44,99 & 46,65 & 3,90 \\
\hline $\mathrm{TiO}_{2}$ & 1,32 & 0,05 & 1,06 & 0,12 & 1,24 & 1,32 & 0,98 & 1,27 & 1,64 & 1,24 & 1,31 & 1,05 & 0,51 \\
\hline $\mathrm{Al}_{2} \mathrm{O}_{3}$ & 8,94 & 1,29 & 8,56 & 25,98 & 8,95 & 8,83 & 8,67 & 8,94 & 10,73 & 9,38 & 9,05 & 9,94 & 5,84 \\
\hline $\mathrm{FeO}$ & 15,51 & 10,85 & 14,80 & 4,00 & 15,45 & 14,98 & 14,94 & 15,38 & 12,42 & 15,07 & 14,94 & 13,49 & 3,47 \\
\hline $\mathrm{Cr}_{2} \mathrm{O}_{3}$ & 0,04 & 0,04 & 0,02 & 0,02 & 0,02 & 0,06 & 0,10 & 0,03 & 0,05 & 0,03 & 0,02 & 0,04 & 0,02 \\
\hline $\mathrm{MnO}$ & 0,45 & 0,28 & 0,46 & 0,04 & 0,37 & 0,43 & 0,37 & 0,37 & 0,22 & 0,39 & 0,40 & 0,34 & 0,12 \\
\hline $\mathrm{MgO}$ & 11,73 & 17,59 & 12,52 & 2,38 & 11,50 & 11,88 & 12,72 & 12,06 & 13,30 & 12,00 & 12,05 & 11,79 & 3,55 \\
\hline $\mathrm{CaO}$ & 11,50 & 12,25 & 11,33 & 0,09 & 11,36 & 11,17 & 11,68 & 11,46 & 11,57 & 11,12 & 11,19 & 10,43 & 3,44 \\
\hline $\mathrm{Na}_{2} \mathrm{O}$ & 1,62 & 0,67 & 1,74 & 2,44 & 1,68 & 1,69 & 1,61 & 1,55 & 1,77 & 1,47 & 1,72 & 1,63 & 0,41 \\
\hline $\mathrm{K}_{2} \mathrm{O}$ & 1,11 & 0,20 & 0,88 & 8,68 & 1,19 & 1,08 & 0,99 & 1,09 & 1,29 & 1,30 & 1,16 & 1,72 & 2,33 \\
\hline $\mathrm{H}_{2} \mathrm{O}$ & 1,99 & 2,14 & 2,01 & 2,15 & 1,97 & 1,98 & 2,03 & 2,01 & 2,02 & 2,00 & 2,00 & 2,03 & 0,06 \\
\hline Total & 98,76 & 101,63 & 99,28 & 97,93 & 97,92 & 97,93 & 100,43 & 99,58 & 98,88 & 99,04 & 98,83 & 99,11 & 1,13 \\
\hline $\mathrm{Si}$ & 6,73 & 7,88 & 6,84 & 7,25 & 6,73 & 6,75 & 6,83 & 6,78 & 6,53 & 6,75 & 6,76 & 6,89 & 0,37 \\
\hline $\mathrm{Ti}$ & 0,15 & 0,01 & 0,12 & 0,01 & 0,14 & 0,15 & 0,11 & 0,14 & 0,18 & 0,14 & 0,15 & 0,12 & 0,06 \\
\hline $\mathrm{Al}$ & 1,59 & 0,21 & 1,50 & 4,27 & 1,61 & 1,58 & 1,51 & 1,57 & 1,88 & 1,66 & 1,60 & 1,72 & 0,95 \\
\hline $\mathrm{Fe}$ & 1,96 & 1,27 & 1,84 & 0,47 & 1,97 & 1,90 & 1,84 & 1,92 & 1,55 & 1,89 & 1,88 & 1,68 & 0,45 \\
\hline $\mathrm{Cr}$ & 0,01 & 0,00 & 0,00 & 0,00 & 0,00 & 0,01 & 0,01 & 0,00 & 0,01 & 0,00 & 0,00 & 0,00 & 0,00 \\
\hline $\mathrm{Mn}$ & 0,06 & 0,03 & 0,06 & 0,01 & 0,05 & 0,06 & 0,05 & 0,05 & 0,03 & 0,05 & 0,05 & 0,04 & 0,02 \\
\hline $\mathrm{Mg}$ & 2,64 & 3,67 & 2,78 & 0,49 & 2,61 & 2,69 & 2,79 & 2,68 & 2,95 & 2,68 & 2,70 & 2,61 & 0,76 \\
\hline $\mathrm{Ca}$ & 1,86 & 1,84 & 1,81 & 0,01 & 1,85 & 1,82 & 1,85 & 1,83 & 1,84 & 1,78 & 1,80 & 1,66 & 0,55 \\
\hline $\mathrm{Na}$ & 0,47 & 0,18 & 0,50 & 0,66 & 0,50 & 0,50 & 0,46 & 0,45 & 0,51 & 0,43 & 0,50 & 0,47 & 0,11 \\
\hline $\mathrm{K}$ & 0,22 & 0,04 & 0,17 & 1,54 & 0,23 & 0,21 & 0,19 & 0,21 & 0,24 & 0,25 & 0,22 & 0,32 & 0,41 \\
\hline $\mathrm{H}$ & 1,86 & 1,84 & 1,81 & 0,01 & 1,85 & 1,82 & 1,85 & 1,83 & 1,84 & 1,78 & 1,80 & 1,66 & 0,55 \\
\hline $\begin{array}{l}\text { Soma dos } \\
\text { cátions }\end{array}$ & 17,532 & 16,957 & 17,434 & 14,721 & 17,539 & 17,472 & 17,471 & 17,452 & 17,563 & 17,403 & 17,459 & 17,18 & 0,83 \\
\hline
\end{tabular}

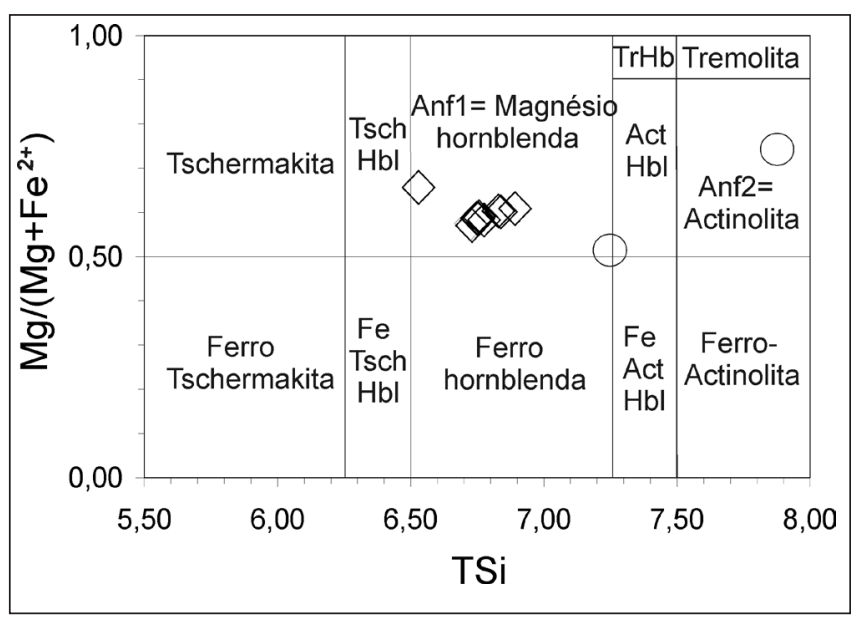

Figura 9 - Classificação do anfibólio do depósito de ouro Cavalo Branco. Abreviações; Tsch = tschermakita, $\mathrm{Hbl}=$ hornblenda, Anf = anfibólio, Act = actinolita, $\mathrm{Fe}=$ ferro e $\operatorname{Tr} \mathrm{Hb}=$ tremolita hornblenda. Mesmas abreviações da figura 7.

calcopirita (Ccpy1) e galena (Gal1) ocorreu durante a alteração fílica (Fig. 7). As composições do ouro e dos outros minerais metálicos serão discutidas adiante.
CLORITA A zona hidrotermal propilítica formou-se após a fílica, na primeira fase de hidrotermalismo que afetou os depósitos Cavalo e Carneiro Branco (Fig. 7). Clorita (Clt2) é o principal mineral indicador dessa zona, sempre acompanhada de quantidades pequenas de epidoto (Ept2) e actinolita (Anf2). A clorita 2 tem composições variadas, iguais as da picnoclorita, brunsvigita, ripidolita e, com menor freqüência, da pseudoturingita (Fig. 13, Tab. 5).

Durante o aumento de temperatura ocorrido no início da reativação termo-tectônica que causou o cisalhamento do depósito Cavalo Branco (Fig. 7), a clorita 3 (Clt3) cristalizou nas clivagens dos fenoblastos de muscovita com composições de talco-clorita, diabantita e picnoclorita (Figs. 7, 8D e 13), ao mesmo tempo que houve disseminação de carbonato (Cabto 1) nas rochas próximas aos planos de cisalhamento. Na segunda fase de hidrotermalismo o anfibólio (Anf1) foi transformado em glomérulos de clorita 4 (Clt4) com composições de picnoclorita, brunsvigita, ripidolita e pseudoturingita. No final dessa fase houve cristalização localizada de ripidolita férrica, denominada clorita "vermiforme" devido à forma tubular e retorcida dos cristais (Clt5, Figs. 7 e $8 I$ ).

Características químicas dos minerais de minério dos depósitos de ouro Cavalo e Carneiro Branco SULFETOS A paragênese sulfetada dos corpos mi- 
Tabela 2 - Análises químicas de feldspato dos depósitos Cavalo e Carneiro Branco (selecionadas dentre 18 análises).

\begin{tabular}{|c|c|c|c|c|c|c|c|c|c|c|c|c|}
\hline Amostra & $\begin{array}{c}\text { L1-P9 } \\
1\end{array}$ & $\begin{array}{c}\text { L1-P9 } \\
1\end{array}$ & $\begin{array}{c}\text { L1-P9 } \\
2\end{array}$ & $\begin{array}{c}\text { L1-P1 } \\
3\end{array}$ & $\begin{array}{c}\text { L1-P9 } \\
6\end{array}$ & $\begin{array}{c}\text { L1-P9 } \\
7\end{array}$ & $\begin{array}{c}\text { L1-P4 } \\
3\end{array}$ & $\begin{array}{c}\text { L1-P4 } \\
12\end{array}$ & $\begin{array}{c}\text { L1-P4 } \\
13\end{array}$ & $\begin{array}{c}\text { L1-P4 } \\
14\end{array}$ & $\begin{array}{c}\text { L1-P4 } \\
15\end{array}$ & $\begin{array}{c}\text { L1-P3 } \\
3\end{array}$ \\
\hline $\mathrm{SiO}_{2}$ & 67,11 & 66,32 & 60,27 & 65,69 & 64,17 & 63,11 & 66,37 & 63,14 & 63,23 & 63,52 & 64,69 & 65,49 \\
\hline $\mathrm{Al}_{2} \mathrm{O}_{3}$ & 20,11 & 21,44 & 24,18 & 21,99 & 18,97 & 18,61 & 20,68 & 18,85 & 19,04 & 18,93 & 21,18 & 20,59 \\
\hline $\mathrm{FeO}$ & 0,00 & 0,56 & 1,26 & 0,46 & 0,04 & 0,09 & 0,05 & 0,07 & 0,07 & 0,10 & 0,42 & 0,56 \\
\hline $\mathrm{BaO}$ & 0,87 & 0,13 & 0,25 & 0,19 & 0,92 & 0,79 & 0,00 & 0,86 & 0,70 & 1,18 & 0,00 & 0,06 \\
\hline $\mathrm{SrO}$ & 0,09 & 0,00 & 0,01 & 0,09 & 0,14 & 0,14 & 0,00 & 0,00 & 0,05 & 0,16 & 0,00 & 0,00 \\
\hline $\mathrm{CaO}$ & 0,54 & 0,68 & 0,82 & 1,21 & 0,08 & 0,04 & 1,13 & 0,00 & 0,03 & 0,10 & 1,02 & 1,86 \\
\hline $\mathrm{Na}_{2} \mathrm{O}$ & 10,04 & 9,80 & 7,63 & 9,81 & 0,76 & 0,55 & 11,35 & 0,34 & 0,80 & 0,82 & 10,04 & 10,82 \\
\hline $\mathrm{K}_{2} \mathrm{O}$ & 2,16 & 2,01 & 4,12 & 1,43 & 15,67 & 15,70 & 0,15 & 16,25 & 15,22 & 15,53 & 1,52 & 0,12 \\
\hline Total & 100,93 & 100,94 & 98,54 & 100,86 & 100,74 & 99,01 & 99,72 & 99,52 & 99,14 & 100,33 & 98,88 & 99,49 \\
\hline $\mathrm{Si}$ & 2,95 & 2,91 & 2,75 & 2,88 & 2,97 & 2,97 & 2,92 & 2,96 & 2,96 & 2,96 & 2,89 & 2,90 \\
\hline $\mathrm{Al}$ & 1,04 & 1,11 & 1,30 & 1,14 & 1,03 & 1,03 & 1,07 & 1,04 & 1,05 & 1,04 & 1,12 & 1,08 \\
\hline $\mathrm{Fe}$ & 0,00 & 0,02 & 0,05 & 0,02 & 0,00 & 0,00 & 0,00 & 0,00 & 0,00 & 0,00 & 0,02 & 0,02 \\
\hline $\mathrm{Ba}$ & 0,02 & 0,00 & 0,01 & 0,00 & 0,02 & 0,02 & 0,00 & 0,02 & 0,01 & 0,02 & 0,00 & 0,00 \\
\hline $\mathrm{Sr}$ & 0,00 & 0,00 & 0,00 & 0,00 & 0,00 & 0,00 & 0,00 & 0,00 & 0,00 & 0,00 & 0,00 & 0,00 \\
\hline $\mathrm{Ca}$ & 0,03 & 0,03 & 0,04 & 0,06 & 0,00 & 0,00 & 0,05 & 0,00 & 0,00 & 0,01 & 0,05 & 0,09 \\
\hline $\mathrm{Na}$ & 0,86 & 0,83 & 0,68 & 0,83 & 0,07 & 0,05 & 0,97 & 0,03 & 0,07 & 0,07 & 0,87 & 0,93 \\
\hline $\mathrm{K}$ & 0,12 & 0,11 & 0,24 & 0,08 & 0,92 & 0,94 & 0,01 & 0,97 & 0,91 & 0,92 & 0,09 & 0,01 \\
\hline Cátions & 5,02 & 5,01 & 5,06 & 5,01 & 5,02 & 5,01 & 5,03 & 5,02 & 5,01 & 5,02 & 5,03 & 5,03 \\
\hline $\mathrm{AB}$ & 85,38 & 85,23 & 70,66 & 85,89 & 6,83 & 5,08 & 94,04 & 3,11 & 7,40 & 7,38 & 86,52 & 90,75 \\
\hline OR & 12,10 & 11,51 & 25,13 & 8,25 & 92,79 & 94,71 & 0,79 & 96,89 & 92,43 & 92,13 & 8,64 & 0,65 \\
\hline AN & 2,53 & 3,26 & 4,21 & 5,86 & 0,38 & 0,21 & 5,17 & 0,00 & 0,17 & 0,49 & 4,84 & 8,60 \\
\hline
\end{tabular}

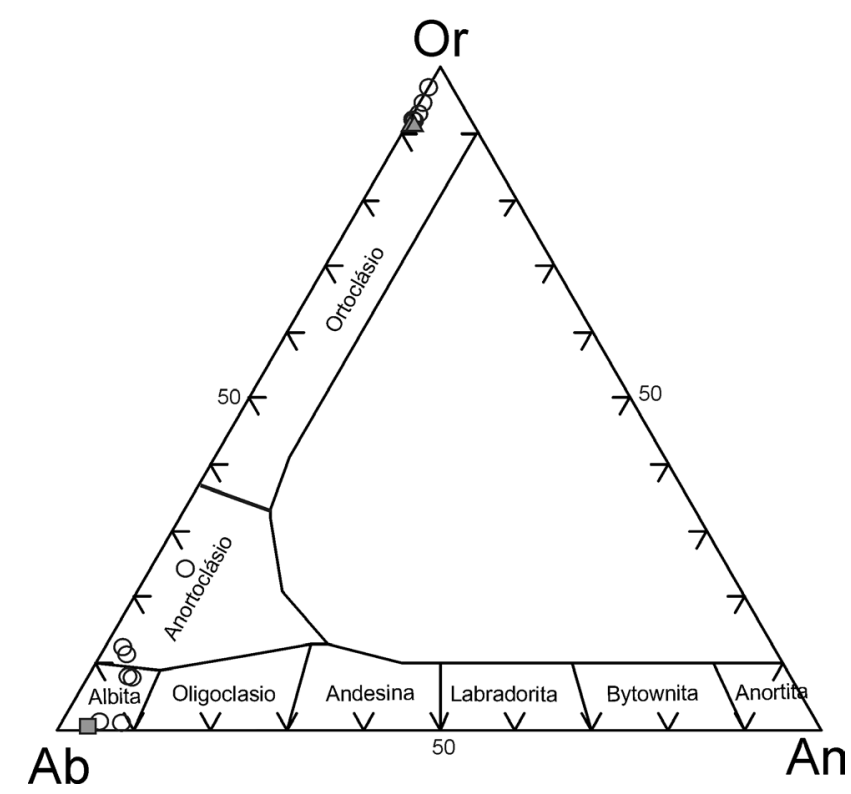

Figura 10 - Composição do feldspato das rochas hidrotermalmente alteradas do depósito de ouro $\mathrm{Ca}$ valo Branco. Círculos = Feldspato K1 sericitizado e envolvido por albita (Plagio 1) durante a alteração tardi-magmática. Quadrados = Plágio 1, plagioclásio primário do diorito. Triângulos $=$ Ortoclásio K1, ortoclásio primário do diorito. Mesmas abreviações da figura 7.

neralizados limita-se a pirita, calcopirita e galena sempre dentro de quartzo (Qzo2). Na zona em que o corpo mineralizado está cisalhado (Cava do Davi, Fig. 5B) a quantidade total de sulfetos contida em quartzo 3 (Qzo3, Fig. 7) varia entre 1 e 4\%. Predomina a pirita, secundada pela calcopirita, à qual se associa o ouro. A galena ocorre como micro-inclusões dentro da pirita e da calcopirita. Na Cava Leste (Fig. 5B) o ouro ocorre livre dentro de quartzo leitoso (Qzo2) e, ocasionalmente, junto à pirita (Py1), que totaliza menos de $1 \%$ em volume do minério.

Pirita (Py1), calcopirita (Ccpy1) e galena (Gal1) cristalizaram durante a alteração fílica, na primeira fase hidrotermal. O cisalhamento mobilizou mecanicamente a pirita (Py2) e a calcopirita (Ccpy2), sem que suas composições mudassem (Figs. 8K e 14, Tab. 6). Todos os sulfetos têm composições com proporções iônicas iguais às das fórmulas estequiométricas.

OURO Durante a formação da zona fílica, o ouro (Au1) cristalizou livre dentro do quartzo (Qzo2, Fig. 7), com formas prismáticas e/ou irregulares, sempre maciças. Este ouro tem cerca de $19,95 \%$ em peso de prata e $0,01 \%$ de cobre (Fig. 15 e Tab. 7, no Anexo). Mobilizado mecanicamente pelo cisalhamento, o ouro 2 (Au2) ocupou micro-fraturas da pirita e da calcopirita (Figs. 7 e 8L) contidas nos sigmóides de quartzo (Qzo3, Fig. 7), com mais prata (média de $23,20 \%$ em peso) e mais cobre (média de $0,51 \%$ ).

DISCUSSÃO Uma solução possível para explicar as formas e atitudes dos filões Cavalo Branco, Carneiro Branco e Fanuelsson seria considerar a zona de cisalhamento Lajeado do Carneiro Branco como a fratura principal, levógira, de um sistema de fraturas conjugadas de primeira ordem, cujo elipsóide de deformação seria 
Tabela 3 - Análises químicas de biotita e de biotita parcialmente cloritizada dos depósitos Cavalo e Carneiro Branco.

\begin{tabular}{|c|c|c|c|c|c|c|c|c|c|c|c|c|}
\hline & $\begin{array}{c}\text { L1-P9 } \\
9\end{array}$ & $\begin{array}{c}\text { L1-P8 } \\
2\end{array}$ & $\begin{array}{c}\text { L1-P3 } \\
6\end{array}$ & $\begin{array}{c}\text { L1-P10 } \\
2\end{array}$ & $\begin{array}{c}\text { L1-P10 } \\
3\end{array}$ & $\begin{array}{c}\text { L1-P10 } \\
4\end{array}$ & $\begin{array}{c}\text { L1-P1 } \\
1\end{array}$ & $\begin{array}{c}\text { L7-P2 } \\
1\end{array}$ & $\begin{array}{c}\text { L1-P3 } \\
2\end{array}$ & $\begin{array}{c}\text { L1-P10 } \\
5\end{array}$ & $\begin{array}{c}\text { L1-P1 } \\
4\end{array}$ & $\begin{array}{c}\text { L1-P4 } \\
11\end{array}$ \\
\hline $\mathrm{SiO}_{2}$ & 36,81 & 37,22 & 37,01 & 37,52 & 37,02 & 43,62 & 37,22 & 35,33 & 37,75 & 58,44 & 50,35 & 50,47 \\
\hline $\mathrm{TiO}_{2}$ & 1,91 & 2,34 & 2,13 & 1,68 & 1,66 & 0,06 & 2,89 & 2,37 & 0,24 & 0,06 & 0,09 & 0,07 \\
\hline $\mathrm{Al}_{2} \mathrm{O}_{3}$ & 15,45 & 15,67 & 15,90 & 15,88 & 15,85 & 9,34 & 15,26 & 15,34 & 31,50 & 18,20 & 28,57 & 28,01 \\
\hline $\mathrm{Cr}_{2} \mathrm{O}_{3}$ & 0,09 & 0,10 & 0,09 & 0,42 & 0,29 & 0,07 & 0,08 & 0,01 & 0,05 & 0,00 & 0,00 & 0,00 \\
\hline $\mathrm{FeO}$ & 16,67 & 16,86 & 16,43 & 16,12 & 16,09 & 16,97 & 16,52 & 16,98 & 1,19 & 1,95 & 3,12 & 3,03 \\
\hline $\mathrm{MnO}$ & 0,29 & 0,32 & 0,30 & 0,30 & 0,29 & 0,27 & 0,28 & 0,18 & 0,02 & 0,05 & 0,01 & 0,04 \\
\hline $\mathrm{MgO}$ & 12,69 & 12,76 & 12,95 & 13,15 & 12,89 & 16,68 & 12,52 & 11,86 & 0,51 & 2,26 & 2,22 & 2,08 \\
\hline $\mathrm{CaO}$ & 0,04 & 0,00 & 0,02 & 0,01 & 0,05 & 6,88 & 0,08 & 0,02 & 9,11 & 0,22 & 0,03 & 0,10 \\
\hline $\mathrm{Na}_{2} \mathrm{O}$ & 0,15 & 0,08 & 0,02 & 0,08 & 0,12 & 0,13 & 0,08 & 0,05 & 0,45 & 0,18 & 1,23 & 1,80 \\
\hline $\mathrm{K}_{2} \mathrm{O}$ & 9,93 & 8,02 & 9,78 & 9,72 & 9,56 & 0,17 & 8,89 & 9,10 & 5,33 & 14,50 & 9,85 & 8,84 \\
\hline $\mathrm{F}$ & 0,67 & 0,22 & 0,55 & 0,52 & 0,41 & 0,22 & 0,45 & 0,41 & 1,13 & 0,13 & 0,00 & 0,00 \\
\hline $\mathrm{Cl}$ & 0,06 & 0,11 & 0,09 & 0,09 & 0,10 & 0,01 & 0,08 & 0,08 & 0,01 & 0,03 & 0,04 & 0,06 \\
\hline $\mathrm{H}_{2} \mathrm{O}$ & 3,55 & 3,79 & 3,64 & 3,68 & 3,69 & 3,99 & 3,68 & 3,56 & 2,45 & 4,39 & 4,48 & 4,45 \\
\hline TOTAL & 98,31 & 97,48 & 98,92 & 99,16 & 98,02 & 98,41 & 98,02 & 95,28 & 87,29 & 100,40 & 99,98 & 98,94 \\
\hline $\mathrm{O}=\mathrm{F}$ & $-0,28$ & $-0,09$ & $-0,23$ & $-0,22$ & $-0,17$ & $-0,09$ & $-0,19$ & $-0,17$ & 0,00 & $-0,05$ & 0,00 & 0,00 \\
\hline Total em óxidos & 98,03 & 97,38 & 98,68 & 98,94 & 97,85 & 98,31 & 97,84 & 95,10 & 87,29 & 100,35 & 99,98 & 98,94 \\
\hline $\mathrm{Si}$ & 5,69 & 5,69 & 5,65 & 5,70 & 5,68 & 6,38 & 5,70 & 5,61 & 7,28 & 7,86 & 6,72 & 6,79 \\
\hline $\mathrm{Ti}$ & 0,22 & 0,27 & 0,24 & 0,19 & 0,19 & 0,01 & 0,33 & 0,28 & 0,04 & 0,01 & 0,01 & 0,01 \\
\hline $\mathrm{Al}$ & 2,81 & 2,82 & 2,86 & 2,84 & 2,87 & 1,61 & 2,76 & 2,87 & 7,16 & 2,88 & 4,50 & 4,44 \\
\hline $\mathrm{Cr}$ & 0,01 & 0,01 & 0,01 & 0,05 & 0,04 & 0,01 & 0,01 & 0,00 & 0,01 & 0,00 & 0,00 & 0,00 \\
\hline $\mathrm{Fe}$ & 2,15 & 2,16 & 2,10 & 2,05 & 2,07 & 2,08 & 2,12 & 2,26 & 0,19 & 0,22 & 0,35 & 0,34 \\
\hline $\mathrm{Mn}$ & 0,04 & 0,04 & 0,04 & 0,04 & 0,04 & 0,03 & 0,04 & 0,02 & 0,00 & 0,01 & 0,00 & 0,00 \\
\hline $\mathrm{Mg}$ & 2,92 & 2,91 & 2,95 & 2,98 & 2,95 & 3,64 & 2,86 & 2,81 & 0,15 & 0,45 & 0,44 & 0,42 \\
\hline $\mathrm{Ca}$ & 0,01 & 0,00 & 0,00 & 0,00 & 0,01 & 1,08 & 0,01 & 0,00 & 1,88 & 0,03 & 0,00 & 0,01 \\
\hline $\mathrm{Na}$ & 0,05 & 0,02 & 0,01 & 0,02 & 0,04 & 0,04 & 0,02 & 0,02 & 0,17 & 0,05 & 0,32 & 0,47 \\
\hline $\mathrm{K}$ & 1,96 & 1,56 & 1,91 & 1,88 & 1,87 & 0,03 & 1,74 & 1,84 & 1,31 & 2,49 & 1,68 & 1,52 \\
\hline $\mathrm{Cl}$ & $-0,01$ & $-0,02$ & $-0,02$ & $-0,02$ & $-0,02$ & 0,00 & $-0,02$ & $-0,02$ & 0,48 & $-0,01$ & $-0,01$ & $-0,01$ \\
\hline $\mathrm{H}$ & 0,00 & 0,00 & 0,00 & 0,00 & 0,00 & 0,00 & 0,00 & 0,00 & 0,00 & 0,00 & 0,00 & 0,00 \\
\hline Cátions & 15,84 & 15,46 & 15,75 & 15,73 & 15,72 & 14,89 & 15,57 & 15,69 & 18,67 & 13,99 & 14,01 & 13,98 \\
\hline
\end{tabular}
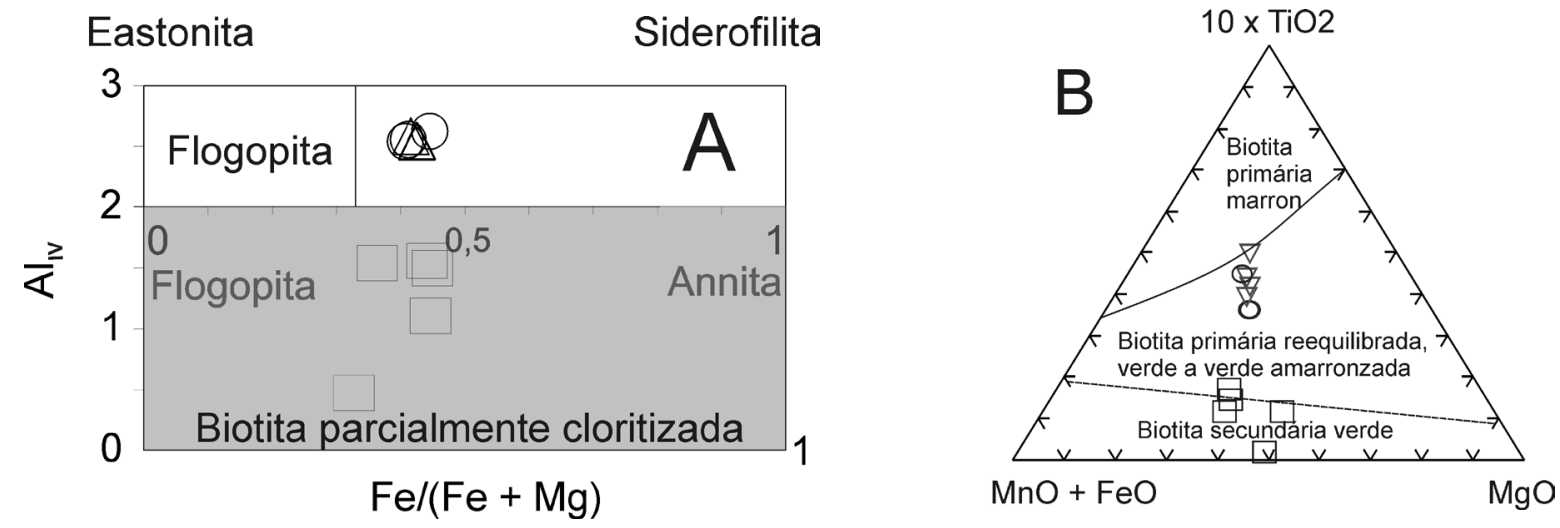

Figura 11 - Composição química da biotita do depósito de ouro Cavalo Branco. (A) Classificação da biotita 1 e 2 e composição de biotita parcialmente transformada em clorita em termos de $\mathrm{Al}_{I V} v \mathrm{~s} . \mathrm{Fe} /$ ( $\mathrm{Fe}+\mathrm{Mg}$ ). (B) Diagrama $\mathrm{MnO}+\mathrm{FeO}$ vs. $10 \mathrm{TiO}{ }_{2}$ vs. $\mathrm{MgO}$ que separa a biotita conforme seu estado de transformação em relação à biotita primária e de equilibrio com o ambiente (Nachit 1986). Triângulos = Biotita 1; Círculos = Biotita 2. Mesmas abreviações da figura 7.

semelhante àquele da figura 3.A. Nesse sistema, a zona de cisalhamento Águas Cristalinas (Figs. 1 e 2A) seria a componente conjugada transpressiva. Esta componente pode ser considerada o cisalhamento principal dextrógiro de um sistema de fraturas conjugadas de segunda ordem, semelhante ao mostrado na figura 3B. Nesse segundo sistema, o filão Cavalo Branco ocuparia a zona de cisalhamento principal, orientada EW, e o Carneiro Branco seria produto do preenchimento das fraturas extensionais, orientadas $\mathrm{N} 15-20^{\circ} \mathrm{W}, 70-75^{\circ} \mathrm{NE}$ (Fig. 1 e 
Tabela 4 - Análises de mica branca dos depósitos de Au Cavalo e Carneiro Branco (Selecionadas dentre 19 análises).

\begin{tabular}{|c|c|c|c|c|c|c|c|c|c|c|}
\hline & $\begin{array}{c}\mathrm{L} 4-\mathrm{P} 2 \\
5\end{array}$ & $\begin{array}{l}\text { L4-P2 } \\
6\end{array}$ & $\begin{array}{c}\text { L4-P5 } \\
8\end{array}$ & $\begin{array}{l}\text { L4-P5 } \\
9\end{array}$ & $\begin{array}{c}\text { L3-P1 } \\
\quad 1\end{array}$ & $\begin{array}{c}\text { L3-P1 } \\
2\end{array}$ & $\begin{array}{l}\text { L3-P1 } \\
3\end{array}$ & $\begin{array}{l}\text { L3-P1 } \\
3\end{array}$ & $\begin{array}{c}\text { Média } \\
\text { (19 análises) }\end{array}$ & $\begin{array}{l}\text { Desv. } \\
\text { pad. }\end{array}$ \\
\hline $\mathrm{SiO}_{2}$ & 46,25 & 46,79 & 46,69 & 48,50 & 45,69 & 45,99 & 46,45 & 46,26 & 47,98 & 3,71 \\
\hline $\mathrm{TiO}_{2}$ & 0,49 & 0,42 & 0,19 & 0,30 & 0,53 & 0,79 & 1,05 & 0,64 & 0,45 & 0,35 \\
\hline $\mathrm{Al}_{2} \mathrm{O}_{3}$ & 36,68 & 36,97 & 36,10 & 34,28 & 34,54 & 35,70 & 34,47 & 35,50 & 33,26 & 5,05 \\
\hline $\mathrm{Cr}_{2} \mathrm{O}_{3}$ & 0,01 & 0,00 & 0,02 & 0,04 & 0,00 & 0,00 & 0,01 & 0,00 & 0,02 & 0,02 \\
\hline $\mathrm{FeO}$ & 1,43 & 1,56 & 1,47 & 1,27 & 3,27 & 2,74 & 3,64 & 2,69 & 2,18 & 0,88 \\
\hline $\mathrm{MnO}$ & 0,05 & 0,02 & 0,01 & 0,01 & 0,01 & 0,00 & 0,00 & 0,00 & 0,02 & 0,02 \\
\hline $\mathrm{MgO}$ & 0,50 & 0,52 & 0,53 & 0,63 & 0,66 & 0,59 & 0,77 & 0,56 & 0,98 & 0,73 \\
\hline $\mathrm{CaO}$ & 0,01 & 0,00 & 0,09 & 0,03 & 0,00 & 0,03 & 0,04 & 0,00 & 0,05 & 0,06 \\
\hline $\mathrm{Na}_{2} \mathrm{O}$ & 0,97 & 1,10 & 0,59 & 0,49 & 1,01 & 1,22 & 1,03 & 1,28 & 0,83 & 0,42 \\
\hline $\mathrm{K}_{2} \mathrm{O}$ & 10,08 & 9,68 & 10,23 & 8,26 & 9,47 & 9,41 & 9,49 & 9,41 & 9,71 & 1,54 \\
\hline $\mathrm{F}$ & 0,13 & 0,21 & 0,46 & 0,26 & 0,00 & 0,21 & 0,16 & 0,21 & 0,12 & 0,13 \\
\hline $\mathrm{Cl}$ & 0,01 & 0,01 & 0,10 & 0,09 & 0,00 & 0,00 & 0,01 & 0,04 & 0,03 & 0,03 \\
\hline $\mathrm{H}_{2} \mathrm{O}$ & 4,50 & 4,49 & 4,28 & 4,37 & 4,47 & 4,44 & 4,46 & 4,42 & 4,45 & 0,08 \\
\hline Total 1 & 101,11 & 101,76 & 100,76 & 98,51 & 99,66 & 101,11 & 101,58 & 101,01 & 100,08 & 1,42 \\
\hline $\mathrm{O}=\mathrm{F}$ & $-0,05$ & $-0,09$ & $-0,19$ & $-0,11$ & 0,00 & $-0,09$ & $-0,07$ & $-0,09$ & & \\
\hline Total 2 & 101,05 & 101,67 & 100,56 & 98,41 & 99,66 & 101,02 & 101,51 & 100,92 & & \\
\hline $\mathrm{Si}$ & 6,08 & 6,11 & 6,19 & 6,45 & 6,13 & 6,08 & 6,14 & 6,12 & 6,38 & 0,50 \\
\hline $\mathrm{Ti}$ & 0,05 & 0,04 & 0,02 & 0,03 & 0,05 & 0,08 & 0,11 & 0,06 & 0,05 & 0,03 \\
\hline $\mathrm{Al}$ & 5,69 & 5,69 & 5,64 & 5,37 & 5,46 & 5,57 & 5,37 & 5,54 & 5,21 & 0,78 \\
\hline $\mathrm{Cr}$ & 0,00 & 0,00 & 0,00 & 0,00 & 0,00 & 0,00 & 0,00 & 0,00 & 0,00 & 0,00 \\
\hline $\mathrm{Fe}$ & 0,16 & 0,17 & 0,16 & 0,14 & 0,37 & 0,30 & 0,40 & 0,30 & 0,24 & 0,10 \\
\hline $\mathrm{Mn}$ & 0,01 & 0,00 & 0,00 & 0,00 & 0,00 & 0,00 & 0,00 & 0,00 & 0,00 & 0,00 \\
\hline $\mathrm{Mg}$ & 0,10 & 0,10 & 0,11 & 0,13 & 0,13 & 0,12 & 0,15 & 0,11 & 0,19 & 0,15 \\
\hline $\mathrm{Ca}$ & 0,00 & 0,00 & 0,01 & 0,00 & 0,00 & 0,00 & 0,01 & 0,00 & 0,01 & 0,01 \\
\hline $\mathrm{Na}$ & 0,25 & 0,28 & 0,15 & 0,13 & 0,26 & 0,31 & 0,26 & 0,33 & 0,21 & 0,11 \\
\hline $\mathrm{K}$ & 1,69 & 1,61 & 1,73 & 1,40 & 1,62 & 1,59 & 1,60 & 1,59 & 1,65 & 0,27 \\
\hline $\mathrm{Cl}$ & 0,00 & 0,00 & 0,02 & 0,02 & 0,00 & 0,00 & 0,00 & 0,01 & 0,01 & 0,01 \\
\hline $\mathrm{H}$ & 0,00 & 0,00 & 0,00 & 0,00 & 0,00 & 0,00 & 0,00 & 0,00 & 0,00 & 0,00 \\
\hline Cátions & 14,02 & 14,00 & 14,00 & 13,64 & 14,03 & 14,05 & 14,04 & 14,04 & 13,93 & 0,18 \\
\hline
\end{tabular}

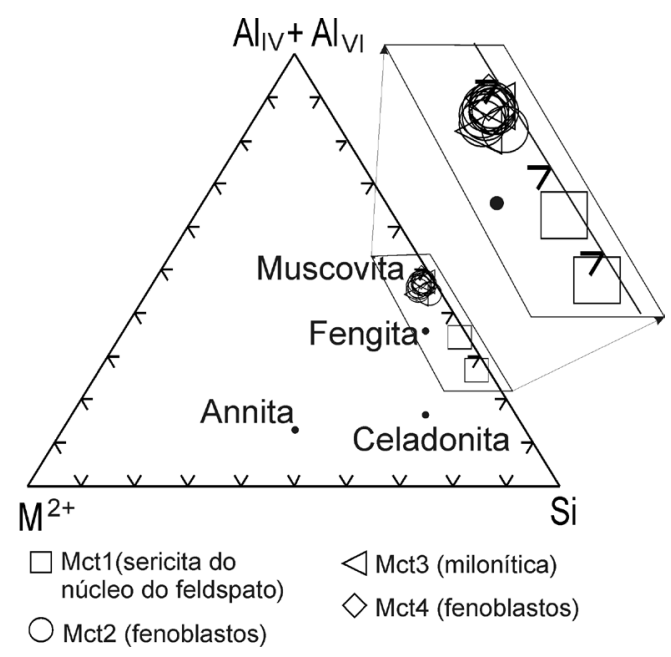

Figura 12 - Classificação da mica branca do depósito de ouro Cavalo Branco, conforme diagrama de Deer et alii (2000, $p$. 296), onde $\mathrm{M}^{2+}$ é a soma dos cátions $\mathrm{Mg}$, $\mathrm{Fe}^{2+}, \mathrm{Cr}^{2+}$, Ti e Li por unidade de fórmula e $\mathrm{Al}_{I V}$ e $\mathrm{Al}_{I V}=$ quantidade de átomos de $\mathrm{Al}$ nas posiçôes tetra e hexavelentes, respectivamente. Mesmas abreviações da figura 7.
Figs. 2A e B). A boudinagem do veio de quartzo do Cavalo Branco (Figs. 4 e 6A, na Cava do Davi) seria conseqüência do cruzamento da foliação milonítica local, com atitude média $\mathrm{N} 78^{\circ} \mathrm{E}, 52^{\circ} \mathrm{SE}$ (Fig. $2 \mathrm{C}$ ), com a foliação paralela ao cisalhamento transpressivo $\mathrm{N} 70^{\circ} \mathrm{E}$, $24^{\circ} \mathrm{SE}$ (Figs. 2B e C).

Uma explicação para as atitudes dos filões Cristalino (Au), Ribeirão do Russo (W) e Tigrano (Au) pode ser obtida considerando um sistema de fraturas conjugadas no qual os veios de quartzo com ouro do Braço Cristalino ocupam a zona de cisalhamento principal e os filões de quartzo com wolfrâmio preenchem as fraturas extensionais (Fig. 3D). Esta situação estrutural explicaria, também, o fatiamento dos veios de quartzo do Braço Cristalino e a mistura do quartzo com o filito encaixante vista nos filões desse depósito.

$\mathrm{O}$ processo que explica a cristalização de fibrolita dentro de fenoblastos de muscovita e dentro de quartzo, pode ser observado nas amostras CA-12 e CA-13 (Fig. 5B). Ambas são xistos aluminosos termometamorfisados, com bandamento composicional e foliação S2 parcialmente preservada. As bandas são de: (1) Cloritoide (Fig. 8H) + fenoblastos de muscovita com núcleo de fibrolita (Fig. 8F) + opaco + sericita. (2) Quartzo (Qzo2/Qzo4) com fibrolita (Fig. 8G) + opaco 
Tabela 5 - Análises químicas de clorita dos depósitos de Au Cavalo e Carneiro Branco (Selecionadas dentre 49 análises).

\begin{tabular}{|c|c|c|c|c|c|c|c|c|c|}
\hline Tipo & Clt 2 & Clt 2 & Clt 2 & Clt 3 & Clt 3 & Clt 3 & Clt 4 & Clt 4 & Clt 5 \\
\hline Mineral & $\begin{array}{l}\text { Bruns- } \\
\text { vigita }\end{array}$ & $\begin{array}{c}\text { Corundo- } \\
\text { filita }\end{array}$ & $\begin{array}{l}\text { Corundo- } \\
\text { filita }\end{array}$ & $\begin{array}{l}\text { Talco- } \\
\text { clorita }\end{array}$ & $\begin{array}{c}\text { Diaban- } \\
\text { tita }\end{array}$ & $\begin{array}{l}\text { Picno- } \\
\text { clorita }\end{array}$ & $\begin{array}{c}\text { Bruns- } \\
\text { vigita }\end{array}$ & $\begin{array}{c}\text { Ripido- } \\
\text { lita }\end{array}$ & $\begin{array}{c}\text { Ripido- } \\
\text { lita }\end{array}$ \\
\hline $\mathrm{SiO}_{2}$ & 26,64 & 26,75 & 23,77 & 45,90 & 32,10 & 27,05 & 25,28 & 24,87 & 21,89 \\
\hline $\mathrm{TiO}_{2}$ & 0,14 & 0,24 & 0,00 & 0,47 & 0,12 & 0,11 & 0,04 & 0,29 & 0,18 \\
\hline $\mathrm{Al}_{2} \mathrm{O}_{3}$ & 22,20 & 18,22 & 38,72 & 36,05 & 23,30 & 18,07 & 17,30 & 21,29 & 20,45 \\
\hline $\mathrm{Cr}_{2} \mathrm{O}_{3}$ & 0,03 & 0,01 & 0,01 & 0,02 & 0,03 & 0,06 & 0,00 & 0,05 & 0,05 \\
\hline $\mathrm{FeO}$ & 24,87 & 20,94 & 26,85 & 2,03 & 25,55 & 21,10 & 36,39 & 30,74 & 34,27 \\
\hline $\mathrm{MnO}$ & 0,16 & 0,22 & 0,28 & 0,08 & 0,09 & 0,15 & 0,17 & 0,18 & 0,13 \\
\hline $\mathrm{MgO}$ & 7,81 & 16,36 & 1,56 & 0,61 & 5,53 & 16,46 & 7,90 & 8,37 & 7,53 \\
\hline $\mathrm{CaO}$ & 0,13 & 0,07 & 0,02 & 0,00 & 0,06 & 0,04 & 0,03 & 0,02 & 0,06 \\
\hline $\mathrm{Na}_{2} \mathrm{O}$ & 0,18 & 0 & 0,00 & 1,11 & 0,16 & 0,00 & 0,09 & 0,00 & 0,00 \\
\hline $\mathrm{K}_{2} \mathrm{O}$ & 2,80 & 0,91 & 0,00 & 9,93 & 1,55 & 0,08 & 0,08 & 0,28 & 0,13 \\
\hline $\mathrm{F}$ & 0,04 & 0,04 & 0,00 & 0,08 & 0,00 & 0,04 & 0,10 & 0,14 & 0,00 \\
\hline $\mathrm{Cl}$ & 0,05 & 0,09 & 0,00 & 0,04 & 0,05 & 0,02 & 0,07 & 0,06 & 0,06 \\
\hline Total & 85,06 & 87,32 & 91,22 & 96,33 & 88,52 & 83,18 & 87,46 & 86,28 & 84,74 \\
\hline $\mathrm{Si}$ & 5,86 & 4,57 & 4,72 & 7,73 & 6,59 & 5,86 & 5,73 & 5,52 & 5,09 \\
\hline $\mathrm{Ti}$ & 0,02 & 0,03 & 0,00 & 0,06 & 0,02 & 0,02 & 0,01 & 0,05 & 0,03 \\
\hline $\mathrm{Al}$ & 5,75 & 3,67 & 9,06 & 7,16 & 5,64 & 4,61 & 4,62 & 5,57 & 5,61 \\
\hline $\mathrm{Cr}$ & 0,01 & 0,00 & 0,00 & 0,00 & 0,01 & 0,01 & 0,00 & 0,01 & 0,01 \\
\hline $\mathrm{Fe}$ & 4,57 & 2,99 & 4,46 & 0,29 & 4,38 & 3,96 & 6,90 & 5,71 & 6,67 \\
\hline $\mathrm{Mn}$ & 0,03 & 0,03 & 0,05 & 0,01 & 0,02 & 0,03 & 0,03 & 0,03 & 0,03 \\
\hline $\mathrm{Mg}$ & 2,56 & 4,17 & 0,46 & 0,15 & 1,69 & 5,32 & 2,67 & 2,77 & 2,61 \\
\hline $\mathrm{Ca}$ & 0,03 & 0,01 & 0,01 & 0,00 & 0,01 & 0,01 & 0,01 & 0,00 & 0,02 \\
\hline $\mathrm{Na}$ & 0,08 & 0 & 0,00 & 0,36 & 0,06 & 0,00 & 0,04 & 0,00 & 0,00 \\
\hline $\mathrm{K}$ & 0,79 & 0 & 0,00 & 2,14 & 0,40 & 0,02 & 0,02 & 0,08 & 0,04 \\
\hline $\mathrm{F}$ & 0,02 & 0 & 0,00 & 0,04 & 0,00 & 0,02 & 0,04 & 0,06 & 0,00 \\
\hline $\mathrm{Cl}$ & 0,01 & 0 & 0,00 & 0,01 & 0,01 & 0,00 & 0,02 & 0,01 & 0,01 \\
\hline Soma dos cátions & 19,72 & 15,66 & 18,75 & 17,95 & 18,83 & 19,86 & 20,09 & 19,81 & 20,11 \\
\hline $\mathrm{Mg} /(\mathrm{Mg}+\mathrm{Fe})$ & 0,36 & & 0,09 & 0,35 & 0,28 & 0,57 & 0,28 & 0,33 & 0,28 \\
\hline $\mathrm{Al}_{\mathrm{IV}}$ & 2,14 & 3,43 & 3,28 & 0,27 & 1,41 & 2,14 & 2,27 & 2,48 & 2,91 \\
\hline $\mathrm{Al}_{\mathrm{VI}}$ & 3,61 & 0,24 & 5,78 & 6,89 & 4,22 & 2,47 & 2,35 & 3,09 & 2,70 \\
\hline
\end{tabular}

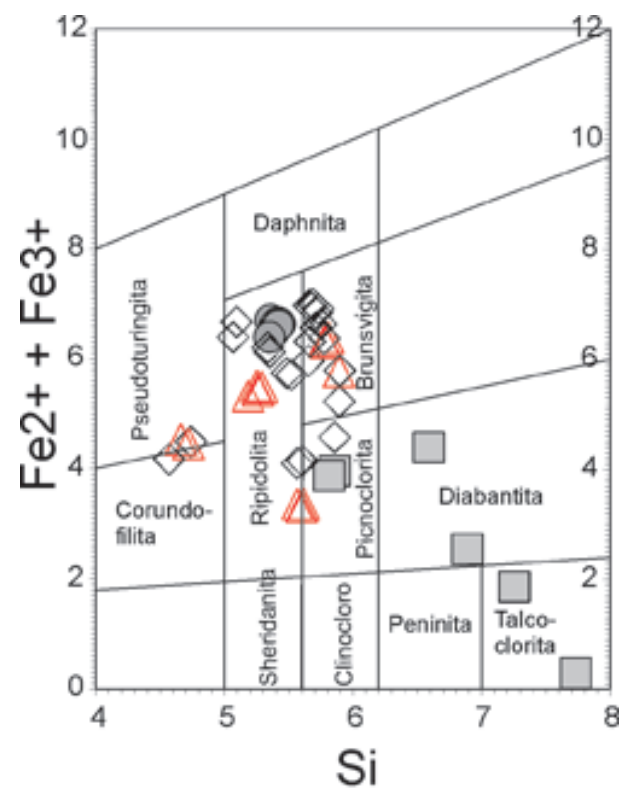

$\triangle \mathrm{Clt} 2 \square \mathrm{Clt3} \triangle \mathrm{Clt} 4 \bigcirc \mathrm{Clt5}$

Figura 13 - Classificação e composição da clorita do depósito de ouro Cavalo Branco conforme o diagrama de Hey (1954). Mesmas abreviações da fig. 7.
+ sericita. (3) Clorita + quartzo com fibrolita + biotita + opaco. (4) Cloritoide + sericita. A coexistência de muscovita e silimanita (fibrolita), de quartzo com fibrolita + muscovita e de cloritóide + fibrolita em graus metamórficos acima do grau médio superior é incomum, pois nestas condições a muscovita dissocia-se para formar feldspato potássico e silimanita, e o cloritóide é instável (Deer, Howie \& Zussman 2000, p.304; Winkler 1977, p.171). Estas paragêneses sugerem a possibilidade da fibrolita ser hidrotermal, gerada pela lixiviação do potássio da muscovita, feita por fluídos ácidos quando a intrusão do diorito causou hidrotermalismo $\left(1^{\text {a }}\right.$ fase hidrotermal, Fig. 7) e/ou quando a granitogênese que gerou as vênulas graníticas reativou o hidrotermalismo ( $2^{\mathrm{a}}$ fase hidrotermal, Fig. 7).

Embora espacialmente associados e parcialmente deformados por cisalhamento, os depósitos de ouro Cavalo e Carneiro Branco têm zonas de alteração primária potássica, fílica e propilítica, características de filões granitogênicos periplutônicos. A deformação foi gerada por esforços relacionados à reativação da zona de cisalhamento Águas Cristalinas e apenas causou mudanças morfológicas no corpo mineralizado, que foi boudinado e segmentado em sigmóides. Os sulfetos foram recristalizados mecanicamente, o que explica 
Tabela 6 - Análises de sulfetos dos depósitos Cavalo e Carneiro Branco (selecionadas dentre 17 análises).

\begin{tabular}{|c|c|c|c|c|c|c|c|c|c|c|c|c|c|}
\hline Mineral & Py & Py & Py & Py & Py & Py & Ccpy & Ccpy & Ccpy & Ccpy & Gal & Gal & Gal \\
\hline Amostra & $\begin{array}{c}\text { S3-P4 } \\
4\end{array}$ & $\begin{array}{c}\text { S5-P2 } \\
5\end{array}$ & $\begin{array}{c}\text { S5-P4 } \\
5\end{array}$ & $\begin{array}{c}\mathrm{S} 2-\mathrm{P} 2 \\
1\end{array}$ & $\begin{array}{c}\text { S4-P2 } \\
2\end{array}$ & $\begin{array}{c}\mathrm{S} 4-\mathrm{P} 2 \\
2\end{array}$ & $\begin{array}{c}\mathrm{S} 2-\mathrm{P} 3 \\
3\end{array}$ & $\begin{array}{c}\mathrm{S} 2-\mathrm{P} 3 \\
3\end{array}$ & $\begin{array}{c}\mathrm{S} 2-\mathrm{P} 2 \\
2\end{array}$ & $\begin{array}{c}\text { S4-P3 } \\
1\end{array}$ & $\begin{array}{c}\mathrm{S} 5-\mathrm{P} 2 \\
2\end{array}$ & $\begin{array}{c}\mathrm{S} 5-\mathrm{P} 2 \\
3\end{array}$ & $\begin{array}{c}\text { S5-P2 } \\
4\end{array}$ \\
\hline S & 53,96 & 53,29 & 53,94 & 53,97 & 53,45 & 54,01 & 34,86 & 34,60 & 35,12 & 34,99 & 14,18 & 13,72 & 13,51 \\
\hline $\mathrm{Fe}$ & 46,93 & 46,42 & 46,65 & 46,61 & 46,08 & 46,43 & 30,23 & 29,54 & 29,95 & 30,08 & 1,52 & 1,66 & 2,02 \\
\hline $\mathrm{Cu}$ & 0,01 & 0,00 & 0,02 & 0,12 & 0,00 & 0,03 & 34,61 & 34,81 & 34,78 & 34,86 & 0,00 & 0,00 & 0,03 \\
\hline $\mathrm{Zn}$ & 0,02 & 0,00 & 0,00 & 0,00 & 0,01 & 0,00 & 0,00 & 0,00 & 0,01 & 0,01 & 0,04 & 0,01 & 0,02 \\
\hline $\mathrm{Pb}$ & 0,00 & 0,00 & 0,00 & 0,00 & 0,00 & 0,00 & 0,00 & 0,00 & 0,00 & 0,00 & 82,06 & 84,31 & 83,26 \\
\hline $\mathrm{Sb}$ & 0,01 & 0,03 & 0,00 & 0,00 & 0,02 & 0,01 & 0,00 & 0,05 & 0,00 & 0,00 & 0,00 & 0,00 & 0,00 \\
\hline $\mathrm{Bi}$ & 0,00 & 0,00 & 0,00 & 0,00 & 0,00 & 0,02 & 0,00 & 0,00 & 0,04 & 0,00 & 0,00 & 0,00 & 0,00 \\
\hline $\mathrm{Ni}$ & 0,00 & 0,22 & 0,11 & 0,00 & 0,05 & 0,05 & 0,01 & 0,02 & 0,01 & 0,00 & 0,00 & 0,00 & 0,00 \\
\hline As & 0,04 & 0,52 & 0,12 & 0,13 & 0,14 & 0,09 & 0,04 & 0,13 & 0,11 & 0,10 & 0,00 & 0,00 & 0,00 \\
\hline $\mathrm{Cd}$ & 0,00 & 0,00 & 0,00 & 0,01 & 0,00 & 0,00 & 0,01 & 0,00 & 0,04 & 0,02 & 0,04 & 0,18 & 0,12 \\
\hline Co & 0,00 & 0,11 & 0,00 & 0,00 & 0,00 & 0,07 & 0,00 & 0,01 & 0,00 & 0,00 & 0,02 & 0,01 & 0,00 \\
\hline $\mathrm{Ag}$ & 0,00 & 0,02 & 0,04 & 0,00 & 0,00 & 0,00 & 0,00 & 0,00 & 0,05 & 0,03 & 1,60 & 0,97 & 1,03 \\
\hline $\mathrm{W}$ & 0,00 & 0,00 & 0,00 & 0,02 & 0,00 & 0,09 & 0,00 & 0,02 & 0,00 & 0,03 & 0,00 & 0,00 & 0,08 \\
\hline $\mathrm{Sn}$ & 0,00 & 0,00 & 0,02 & 0,02 & 0,00 & 0,01 & 0,01 & 0,02 & 0,00 & 0,00 & 0,02 & 0,02 & 0,00 \\
\hline Soma & 100,98 & 100,60 & 100,90 & 100,88 & 99,76 & 100,82 & 99,77 & 99,19 & 100,10 & 100,11 & 99,47 & 100,88 & 100,07 \\
\hline $\mathrm{S}$ & 66,67 & 66,32 & 66,71 & 66,74 & 66,80 & 66,83 & 50,01 & 49,99 & 50,21 & 50,05 & 50,16 & 48,86 & 48,37 \\
\hline $\mathrm{Fe}$ & 33,29 & 33,00 & 33,12 & 33,10 & 33,07 & 32,99 & 24,90 & 24,50 & 24,58 & 24,70 & 3,08 & 3,39 & 4,16 \\
\hline $\mathrm{Cu}$ & 0,01 & 0,00 & 0,01 & 0,08 & 0,00 & 0,02 & 25,05 & 25,38 & 25,09 & 25,16 & 0,00 & 0,00 & 0,06 \\
\hline $\mathrm{Zn}$ & 0,01 & 0,00 & 0,00 & 0,00 & 0,01 & 0,00 & 0,00 & 0,00 & 0,01 & 0,00 & 0,07 & 0,02 & 0,03 \\
\hline $\mathrm{Pb}$ & 0,00 & 0,00 & 0,00 & 0,00 & 0,00 & 0,00 & 0,00 & 0,00 & 0,00 & 0,00 & 44,92 & 46,47 & 46,13 \\
\hline $\mathrm{Sb}$ & 0,01 & 0,01 & 0,00 & 0,00 & 0,01 & 0,01 & 0,00 & 0,02 & 0,00 & 0,00 & 0,00 & 0,00 & 0,00 \\
\hline $\mathrm{Bi}$ & 0,00 & 0,00 & 0,00 & 0,00 & 0,00 & 0,00 & 0,00 & 0,00 & 0,01 & 0,00 & 0,00 & 0,00 & 0,00 \\
\hline $\mathrm{Ni}$ & 0,00 & 0,15 & 0,08 & 0,00 & 0,04 & 0,04 & 0,01 & 0,01 & 0,00 & 0,00 & 0,00 & 0,01 & 0,00 \\
\hline As & 0,02 & 0,28 & 0,06 & 0,07 & 0,08 & 0,05 & 0,03 & 0,08 & 0,07 & 0,06 & 0,00 & 0,00 & 0,00 \\
\hline $\mathrm{Cd}$ & 0,00 & 0,00 & 0,00 & 0,00 & 0,00 & 0,00 & 0,01 & 0,00 & 0,02 & 0,01 & 0,04 & 0,19 & 0,12 \\
\hline Co & 0,00 & 0,08 & 0,00 & 0,00 & 0,00 & 0,05 & 0,00 & 0,00 & 0,00 & 0,00 & 0,04 & 0,01 & 0,00 \\
\hline $\mathrm{Ag}$ & 0,00 & 0,01 & 0,02 & 0,00 & 0,00 & 0,00 & 0,00 & 0,00 & 0,02 & 0,01 & 1,68 & 1,03 & 1,10 \\
\hline W & 0,00 & 0,00 & 0,00 & 0,00 & 0,00 & 0,02 & 0,00 & 0,01 & 0,00 & 0,01 & 0,00 & 0,00 & 0,05 \\
\hline $\mathrm{Sn}$ & 0,00 & 0,00 & 0,01 & 0,01 & 0,00 & 0,00 & 0,00 & 0,01 & 0,00 & 0,00 & 0,02 & 0,02 & 0,00 \\
\hline Normal. & 100,00 & 99,84 & 100,00 & 100,00 & 100,00 & 100,00 & 100,00 & 100,00 & 100,00 & 100,00 & 100,00 & 100,00 & 100,00 \\
\hline
\end{tabular}

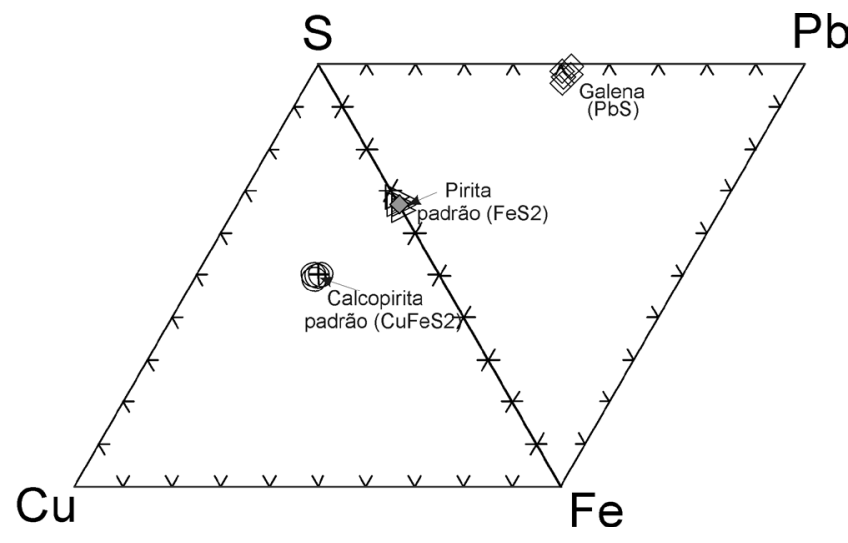

Figura 14 - Triângulos Cu vs. S vs. Fe e Fe vs. Svs. Pb (Vaughan \& Craig 1978) que mostram as composições dos sulfetos do minério do depósito Cavalo Branco (SC). Mesmas abreviações da figura 7. terem as mesmas composições quando disseminados e quando cristalizados em fraturas e nos "boudins". Na parte cisalhada do corpo mineralizado (Cava do Davi) há mais ouro e o ouro mobilizado e recristalizado (Au2) é pouco mais rico em prata e em cobre que o primário (Cava Leste). Não foram percebidas evidências que permitam concluir se estas mudanças foram causadas pelo aporte de ouro novo, via zona de cisalhamento, ou se são apenas conseqüência da recristalização do ouro primário em um ambiente hidrotermal diferente (= segunda fase de hidrotermalismo), gerado pelas intrusões de vênulas graníticas. A carbonatação das rochas e a cloritização intensa (Ctl 4 e Clt 5) indicam o aporte de fluídos novos ao ambiente mineralizado. Embora este tipo de alteração seja mais comum em zonas de cisalhamento, também nesse caso não é possível ter certeza da origem desses fluídos, se do cisalhamento ou da grani- 
Tabela 7 - Análises do ouro dos depósitos Cavalo e Carneiro Branco.

\begin{tabular}{|c|c|c|c|c|c|c|c|c|c|c|c|c|c|}
\hline \multirow[t]{2}{*}{ Amostra } & \multirow{2}{*}{$\begin{array}{c}\text { Tipo } \\
\text { de } \\
\text { Ouro }\end{array}$} & \multicolumn{6}{|c|}{ Teor em \% } & \multicolumn{6}{|c|}{ Cátions - Normalizado } \\
\hline & & $\mathrm{Au}$ & $\mathrm{Ag}$ & $\mathrm{Pd}$ & $\mathrm{Te}$ & $\mathrm{Cu}$ & Soma & $\mathrm{Au}$ & $\mathrm{Ag}$ & $\mathrm{Pd}$ & $\mathrm{Te}$ & $\mathrm{Cu}$ & Normalizado \\
\hline S6-P2-16 & $\mathrm{Au} 2$ & 77,39 & 23,05 & 0,00 & 0,11 & 0,08 & 99,62 & 63,59 & 36,08 & 0,00 & 0,14 & 0,19 & 100,00 \\
\hline S6-P2-17 & Au2 & 76,10 & 23,31 & 0,00 & 0,09 & 1,05 & 99,56 & 61,43 & 35,83 & 0,00 & 0,11 & 2,63 & 100,00 \\
\hline S4-P3-3 & $\mathrm{Au} 2$ & 77,36 & 22,69 & 0,00 & 0,03 & 0,72 & 99,80 & 62,95 & 35,20 & 0,00 & 0,04 & 1,82 & 100,00 \\
\hline S4-P3-4 & $\mathrm{Au} 2$ & 76,30 & 23,73 & 0,00 & 0,00 & 1,23 & 100,26 & 60,91 & 36,05 & 0,00 & 0,00 & 3,05 & 100,00 \\
\hline Média & Au2 & 76,79 & 23,20 & 0,00 & 0,06 & 0,77 & 99,81 & 62,22 & 35,79 & 0,00 & 0,07 & 1,92 & 100,00 \\
\hline $\begin{array}{l}\text { Desvio } \\
\text { Padrão }\end{array}$ & $\mathrm{Au} 2$ & 0,68 & 0,44 & 0,00 & 0,05 & 0,51 & 0,32 & 1,26 & 0,41 & 0,00 & 0,06 & 1,26 & 0,00 \\
\hline S5-P4-2 & Au1 & 81,04 & 19,15 & 0,00 & 0,05 & 0,02 & 99,25 & 68,71 & 31,19 & 0,00 & 0,07 & 0,04 & 100,00 \\
\hline S5-P4-3 & Aul & 81,71 & 18,61 & 0,00 & 0,00 & 0,01 & 99,33 & 69,51 & 30,46 & 0,00 & 0,01 & 0,02 & 100,00 \\
\hline S5-P4-4 & Aul & 77,92 & 22,10 & 0,00 & 0,05 & 0,00 & 99,07 & 64,84 & 35,10 & 0,00 & 0,07 & 0,00 & 100,00 \\
\hline Média & Aul & 80,22 & 19,95 & 0,00 & 0,04 & 0,01 & 99,22 & 67,69 & 32,25 & 0,00 & 0,05 & 0,02 & 100,00 \\
\hline $\begin{array}{l}\text { Desvio } \\
\text { Padrão }\end{array}$ & Aul & 2,02 & 1,88 & 0,00 & 0,03 & 0,01 & 0,13 & 2,50 & 2,49 & 0,00 & 0,03 & 0,02 & 0,00 \\
\hline
\end{tabular}

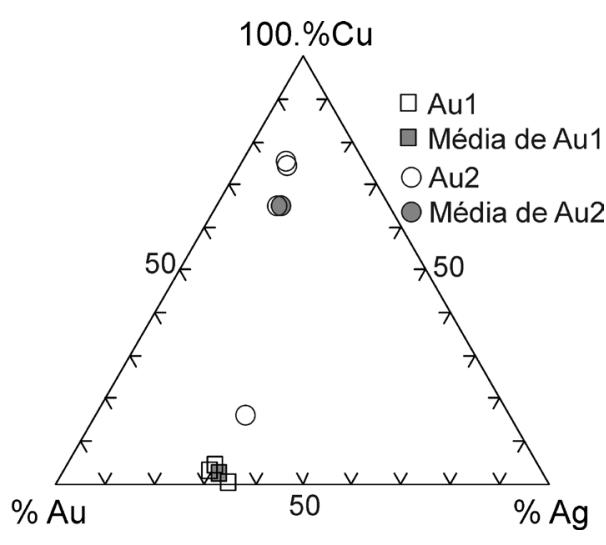

Figura 15 - Triângulo Au vs. 100.Cu vs. Ag que mostra as composições do ouro do minério do depósito Cavalo Branco (SC). Mesmas abreviações da figura 7 .

togênese que gerou as vênulas graníticas.

Caldasso et al. (1995) defendem que a granitização Faxinal, sienítica e mesocrática, tenha sido a última granitogênese da região de Botuverá. $\mathrm{O}$ diorito Cavalo Branco e as vênulas de granito rosado (Fig. 6) que cortam o diorito são posteriores aos granitos das fácies Valsungana e Guabiruba e são diferentes dos granitos da fácies Faxinal. Ou correspondem a novas granitogêneses ou são fácies até então não percebidas das granitogêneses descritas por Caldasso et al. (1995).
CONCLUSÕES Embora associados a uma zona de cisalhamento, os veios de quartzo com ouro dos depósitos Cavalo e Carneiro Branco estão envolvidos por zonas de alteração hidrotermal potássica, fílica e propilítica, típicas de filões granitogênicos periplutônicos, formadas durante a primeira fase hidrotermal (Fig. 7). Após a formação dos veios de quartzo com ouro houve reativação do cisalhamento, recorrência da alteração hidrotermal e os corpos mineralizados foram parcialmente cisalhados.

A foliação e boudinagem de parte do filão, geradas pelo cisalhamento, e a cristalização de clorita "vermiforme" e de carbonato sugerem uma relação genética do minério com o cisalhamento e a participação de fluídos "mesotermais", mas não são consideradas suficientes para que se classifique o depósito como "mesotermal" ou "orogênico", no sentido de Groves et al. (1998). Isto é corroborado pela permanência, após o cisalhamento, das zonas hidrotermais granitogênicas e pela constância da composição dos sulfetos, apenas mobilizados mecanicamente. A cristalização de glomérulos de clorita (Clt4), de clorita "vermiforme" (Clt5), Fig. 7) e de carbonato (Cabto 2) está relacionada a uma segunda fase hidrotermal, associada aos diques e vênulas de granito rosado.

O diorito Cavalo Branco e as vênulas de granito rosado nele contidas são fácies graníticas diferentes daquelas conhecidas na região de Botuverá (SC). Podem corresponder a novas granitogêneses ou são recorrências das fácies conhecidas, até então não percebidas. Um estudo petrológico a ser feito com essas rochas poderá resolver este problema.

\section{Referências}

Babinsky M., Chemale Jr. F., Hartmann L.A., Van Schmus W.R. e Silva L.C. 1996. Juvenile accretion at 750-700 Ma in southern Brazil. Geology 24:439-442.

Babinsky M., Chemale Jr. F., Hartmann L.A., Van Schmus
W.R. e Silva L.C. 1997. U-Pb and Sm-Nd geochronology of the Neoproterozoic granitic-gneissic Dom Feliciano Belt, Southern Brasil. Jour. South Am. Earth Sci. 10:263-274. 
Basei M.A.S. 1985. O Cinturão Don Feliciano em Santa Catarina. Tese de Doutoramento, Instituto de Geociências, Universidade de São Paulo, 190 p.

Basei M.S.A. 2000. Geologia e modelagem geotectônica dos terrenos das regiões sul-oriental brasileira e uruguaia - Possíveis correlações com províncias similares do sudoeste africano. Tese de Livre Docência. Instituto de Geociências, Universidade de São Paulo, 123 p.

Caldasso A.L.S., Krebs A.S.J., Silva M.A.S., Camozzato E, Ramgrab G.E. 1995. Boletim Explicativo do Mapa Geológico da Folha Botuverá (SC), SG.22-Z-D-I-2. Programa Levantamentos Geológicos Básicos do Brasil. Brasília, CPRM, MME, 303 p.

Castro N.A. 1997. Contribuição ao conhecimento geológicometalogenético associado aos granitóides intrusivos no Grupo Brusque (SC) com base em informações geológicas, aerogamaespectrométricas e Landsat/TM-5. Dissertação de Mestrado, Instituto de Geociências, UNICAMP, $139 \mathrm{p}$.

Chemale Jr. F., Hatmann L.A., Silva L.C. 1995. Stratigraphy and tectonism of Brasiliano Cycle in Southern Brazil. In: M. McNeall (ed.) Proceedings Volume on Proterozoic Crust and Metallogenetic Evolution. Communications of Geol. Soc. of Namíbia v. 10, p.151-166.

Deer W.A., Howie R.A., Zussman J. 2000 - "Minerais constituintes das Rochas - Uma Introdução". Tradução de Carlos A.R. Macedo, 4a edição, Fund. Calouste Gulbenkian, $727 \mathrm{p}$.

Groves D.I., Goldfarb R.J., Gebre-Marian M, Hagemann S.G., Robert F. 1998. Orogenic gold deposits: a proposed classification in the context of their crustal distribution and relationship to other gold deposit types. Ore Geology Review 13:7-18.

Hartmann L.A. 1998. Deepest exposure crust of Brazil Geochemisty of Paleoproterozoic depleted Santa Maria Chico granulites. Gondwana Research 1:1-13.

Hartmann L.A., Nardi L.V.S., Formoso M.L.L., Remus M.V.D., Lima E.F., Mexias A.S. 1999a. Magmatism and metallogeny in the crustal evolution of Rio Grande do Sul Shield. Pesquisas, UFRGS, 26:73-92.

Hartmann L.A., Santos J.O., Leite J.A.D., McNaughton N.J. 1999b. Deepest exposure crust of Brazil - SHRIMP atablishes three events. Geology 27:947-950.

Hartmann L.A., Leite J.A.D., Silva L.C., Remus M.V.D., McNaughton N.J., Groves D.I., Fletcher I.R., Santos J.O.S., Vasconcellos M.A.Z. 2000. Advances in SHRIMP geochronology and their impact on understanding the tectonic and metallogenic evolution of Southern Brazil. Australian Jour. Earth Sci., 47:829-844.

Hey M.H. 1954. A new review of the chlorites. Min. Magazine., 30:266-281.

Leake B.E. 1997. Nomenclature of amphiboles: Report of the Sub-Committee on Amphiboles of the International Mineralogical Association, Commission on New Minerals and Minerals Names. Amer. Mineral., 82:1019-1037.

Leite J.A.D., Hartmann L.A., McNaughton N.J., Chemale Jr.
F. 1998. SHRIMP U/Pb zircon geochronology of Neoproterozoic juvenile and crustal-reworked terranes in southernmost Brazil. Int. Geol. Rev., 40:688-705.

Machado N., Koppe J.C., Hartmann L.A. 1990. A Late Proterozoic U-Pb age for the Bossoroca Belt, Rio Grande do Sul, Brazil. Jour. South Am. Earth Sci., 3:87-90.

Nachit H. 1986. Contribution à l'étude analytique des biotites des granitóides - Applications typologiques. Tese de Doutorado, Brest, Université de Bretagne Occidentale, $276 \mathrm{p}$.

Remus M.V.D., McNaugton N.J., Hartmann L.A., Koppe J.C., Groves D.I., Pinto V.M. 1999. Gold in the Neoproterozoic juvenile Bossoroca volcanic arc of southernmost Brazil - Isotopic constraints on timing and sources of ore. Jour. South Am. Earth Sci., 4:1-18.

Remus M.V.D., Hartmann L.A., McNaugton N.J., Groves D.I., Fletcher I.R. 2000a. The link between hydrothermal epigenetic copper mineralization and the Caçapava Granite of the Brasiliano Cycle in southern Brazil. Jour. South Am. Earth Sci., 12:349-366.

Remus M.V.D., Hartmann L.A., McNaugton N.J., Groves D.I., Reischl J.L. 2000b. A distal magmatic-hydrothermal origin for the Camaquã $\mathrm{Cu}(\mathrm{Au}-\mathrm{Ag})$ and Santa Maria $\mathrm{Pb}, \mathrm{Zn}(\mathrm{Cu}-\mathrm{Ag})$ deposits, southern Brazil. Gondwana Research, 3:155-174.

Silva L.C., Hartmann L.A., McNaughton N.J., Fletcher I.R. 1999. SHRIMP U/Pb zircon timing of Neoproterozoic granitic magmatism and deformation in the Pelotas Batolith in southernmost Brazil. Int. Geol. Rev., 41:531551.

Silva L.C., Gresse P., Scheepers R., McNaughton L.A., Hartmann L.A., Fletcher I.R. 2000. U-Pb SHRIMP and Sm$\mathrm{Nd}$ age constranits on the timing and sources of the PanAfrican Cape Granite Suíte, South África. Jour. African Earth Sci, 30:795-815.

Silva L.C. 2006. Geocronologia aplicada ao mapeamento regional com ênfase na técnica U-Pb SHRIMP e ilustrada com estudos de casos brasileiros. Disponível em: www. cprm.gov.br, Acessado em novembro 2007, Publicações Especiais, CPRM, n ${ }^{\circ} 1,132 p$.

Silva M.A.S. \& Krebs A.S.J. 1982. Projeto wolframita no Estado de Santa Catarina. Porto Alegre, DNPM/CPRM, 5 v. Relatório inédito.

Silva M.A.S., Krebs A.S.J. e Camozzato E. 1982. Avaliação dos depósitos wolframíticos do Complexo Metamórfico Brusque, SC. Vol. II - Área do Russo. Acta Geológica Leopoldensia, 6(12):95-151.

Vaughan D.J. \& Craig J.R. 1978. Mineral chemistry of metal sulfides. Cambridge Univ. Press, 324 p.

Winkler H.G. 1977. "Petrogênese das Rochas Metamórficas". Tradução de C. Burger Jr. e Ruy O. de Freitas, $3^{\mathrm{a}}$ edição, Editora Edgard Blucher, 254p.

Manuscrito AE 089/2006 Submetido em 11 de outubro de 2006 Aceito em 15 de maio de 2007 